\title{
Clinical experimentation with aerosol antibiotics: current and future methods of administration
}

This article was published in the following Dove Press journal:

Drug Design, Development and Therapy

I October 2013

Number of times this article has been viewed

\section{Paul Zarogoulidis ${ }^{1,2}$ \\ loannis Kioumis' \\ Konstantinos Porpodis' \\ Dionysios Spyratos 1 \\ Kosmas Tsakiridis ${ }^{3}$ \\ Haidong Huang ${ }^{4}$ \\ Qiang $\mathrm{Li}^{4}$ \\ J Francis Turner ${ }^{5}$ \\ Robert Browning ${ }^{6}$ \\ Wolfgang Hohenforst- \\ Schmidt ${ }^{7}$ \\ Konstantinos Zarogoulidis'}

'Pulmonary Department, G Papanikolaou General Hospital, Aristotle University of Thessaloniki, Thessaloniki, Greece;

${ }^{2}$ Department of Interventional

Pneumology, Ruhrlandklinik, West

German Lung Center, University

Hospital, University Duisburg-Essen,

Essen, Germany; ${ }^{3}$ Cardiothoracic

Surgery Department, Saint Luke

Private Hospital of Health Excellence,

Thessaloniki, Greece; ${ }^{4}$ Department of

Respiratory Diseases, Shanghai Hospital/

First Affiliated Hospital of the Second

Military Medical University, Shanghai,

People's Republic of China; ${ }^{5}$ Pulmonary

Medicine, University of Nevada School

of Medicine, National Supercomputing

Center for Energy and the Environment

University of Nevada, Las Vegas, NV,

USA; ${ }^{6}$ Pulmonary and Critical Care

Medicine, Interventional Pulmonology,

National Naval Medical Center, Walter

Reed Army Medical Center, Bethesda,

MD, USA; 'II Medical Department,

Regional Clinic of Coburg, University

of Wuerzburg, Coburg, Germany

Correspondence: Paul Zarogoulidis Pulmonary Department, G Papanikolaou General Hospital, Aristotle University of Thessaloniki, Thessaloniki, Greece

Tel +3023 I 0992433

Fax +30 23I 0992432

Email pzarog@hotmail.com
Abstract: Currently almost all antibiotics are administered by the intravenous route. Since several systems and situations require more efficient methods of administration, investigation and experimentation in drug design has produced local treatment modalities. Administration of antibiotics in aerosol form is one of the treatment methods of increasing interest. As the field of drug nanotechnology grows, new molecules have been produced and combined with aerosol production systems. In the current review, we discuss the efficiency of aerosol antibiotic studies along with aerosol production systems. The different parts of the aerosol antibiotic methodology are presented. Additionally, information regarding the drug molecules used is presented and future applications of this method are discussed.

Keywords: antibiotics, aerosol, nebulizers

\section{Introduction}

Currently most antibiotics are administered via the intravenous route. ${ }^{1}$ However, it has been observed in clinical practice that there are several situations where the necessary concentration of the administered antibiotic is not reached in the target tissue/system. A clear example of this clinical situation where optimal antibiotic concentrations are necessary is bone infection. Local antibiotic administration using a system able to achieve higher antibiotic concentrations locally increases local disease control. ${ }^{2}$ Pulmonary infection is another situation where antibiotics need to reach high concentrations locally. ${ }^{3}$ In addition, in most pulmonary diseases, including asthma, chronic obstructive pulmonary disease, and cystic fibrosis, the defense mechanisms of the respiratory tract are operating subnormally. ${ }^{4}$ These defense mechanisms can be summarized as beating cilia, mucus, the cough reflex, and local macrophages. In the event of malfunction of these defense mechanisms, it is easy for microorganisms that colonize the lung parenchyma to proliferate and cause infection. There are several factors affecting the efficient deposition of an aerosolized pharmaceutical, including: the flow rate produced $; 5$ design of the residual cup $;{ }^{9}$ residual cup loading $;{ }^{10,11}$ residual cup filling at the start of drug administration; $;{ }^{10}$ tapping of the residual cup during nebulization; ${ }^{12}$ charge on the drug molecules $;{ }^{13}$ environment of the respiratory tract (humidity $>99 \%$ and airways temperature $37^{\circ} \mathrm{C}$ ); chemical structure of droplets; ${ }^{14}$ droplet size produced $(<5 \mu \mathrm{m}){ }^{15}$ viscosity; surface tension; and concentration of the drug solution. ${ }^{16}$ In order for the aerosol to reach the distal airways, the maximum droplet size produced must not exceed $5 \mu \mathrm{m}$. It has been observed that, due to the respiratory tract environment $\left(>99 \%\right.$ humidity and $\left.37^{\circ} \mathrm{C}\right)$, chemical structure, and concentration of salts, the molecules of the aerosol increase in size between $25 \%$ to 
$50 \%$ of the original produced size. ${ }^{17}$ The increased flow rate is responsible for reducing the nebulization time. ${ }^{5,8,12}$ Several authors have also proposed refilling of the residual cup when the solution volume reaches half of the initial value in order to produce droplets $<5 \mu \mathrm{m}$ in size. The number of fillings should not exceed two, because the concentration of the drug solution will drop significantly. ${ }^{17}$ Moreover; the lung parenchyma, if extended, measures $100 \mathrm{~m}^{2}$, and is actually a huge membrane where oxygen enters the circulation through the small vessels surrounding the alveoli. ${ }^{18}$ Underlying respiratory disease or opportunistic infection will negatively affect distribution of the aerosol. However, from our experience with inhaled insulin, the available information indicates that aerosol therapy can still be administered, but the dose should be changed and closer monitoring of the relevant laboratory values is necessary. ${ }^{19}$

New recently published insights regarding aerosol antibiotics in patients with underlying respiratory disease or opportunistic infection indicate that local administration has an immunomodulatory effect and that the inflammatory response to the infection is kept to a minimum. ${ }^{20}$ Tracheal and alveolar macrophages remain active, and the inflammation associated with the infection is kept under control at the same time. ${ }^{21}$ Another reason why we would like to be able to administer antibiotics locally is that the antibiotic solution undergoes minimal systemic metabolism when administered via this route. In a number of cases, the intravenously administered dose has to be reduced because of impaired renal or liver function. It has been previously observed that aerosol antibiotic treatment is also efficient when lower antibiotic drug concentration is administered. ${ }^{22-26}$ Several aerosol antibiotics are currently approved, including tobramycin, ${ }^{26-33}$ aztreonam lysine, ${ }^{34-40}$ and colistimethate sodium, ${ }^{41-46}$ and other new formulations are under development, including polymyxins, ${ }^{47}$ aminoglycosides, ${ }^{48-53}$ fluoroquinolones, ${ }^{54,55}$ and fosfomycin. ${ }^{56}$ Several respiratory diseases, including chronic obstructive pulmonary disease, asthma, and cystic fibrosis, show changes in parameters of the respiratory system, eg, sputum viscosity. Novel nanomolecules bypassing these obstacles to distribution have been reported. ${ }^{57,58}$ In the current mini-review, published clinical trials, new information regarding aerosol production systems, ${ }^{48,57,59-63}$ and novel nanoformulations ${ }^{58,64-72}$ are discussed.

\section{Search methods}

We performed an electronic article search using the PubMed, Google Scholar, Medscape, and Scopus databases, using combinations of the following search terms: "aerosol antibiotics", "aerosol nanoparticles", "aerosol production", and "aerosol antibiotic studies". All types of articles (randomized controlled trials, clinical observational cohort studies, review articles, case reports) were included. Selected references from the articles identified were searched further, with no language restrictions.

\section{Fosfomycin/tobramycin}

The study by Trapnell et $\mathrm{al}^{56}$ screened 162 patients, of whom 121 completed the trial. The mean patient age was 32 years and two different drug combinations were administered, ie, $160 / 40 \mathrm{mg}$ and $80 / 20 \mathrm{mg}$. The administration system was an eFlow ${ }^{\circledR}$ nebulizer system (PARI Pharma $\mathrm{GmbH}$, Starnberg, Germany). Safety and efficiency were recorded using spirometry, the Cystic Fibrosis Questionnaire-Revised (CFQ-R), and recording of adverse effects in the respiratory tract. Upon inclusion in the protocol, patients were stratified according to their performance on spirometry, and Pseudomonas aeruginosa was required to be present in expectorated sputum, in previous examinations. Two major points regarding treatment should be noted. First, all patients received bronchodilation before administration of the aerosol antibiotic independently of their regular inhalation therapy. Second, there were 12 hospitalizations due to disease exacerbation after aerosol administration according to the treating physician. Major positive results included a relative increase in forced expiratory volume in one second $\left(\mathrm{FEV}_{1}\right)$, lower sputum $P$. aeruginosa density on the $80 / 20 \mathrm{mg}$ dose, and fewer adverse effects on this dose. No major therapeutic differences were observed between the two groups ${ }^{56}$ (Table 1).

\section{Tobramycin alone}

Inhaled tobramycin was administered as $300 \mathrm{mg}$ twice daily in a multicenter, placebo-controlled, 24-week study. Once again, changes in $\mathrm{FEV}_{1}$ and sputum $P$. aeruginosa density were recorded, along with adverse effects. Administration of the aerosol was performed using two nebulizers, ie, the LC Plus ${ }^{\circledR}$ jet nebulizer (PARI Pharma $\mathrm{GmbH}$ ) and the Pulmo-Aide compressor (DeVilbiss, Glendale Heights, IL, USA). The patients were again stratified according to $\mathrm{FEV}_{1}$ and sputum $P$. aeruginosa density. In addition, the patients were instructed to wear nose clips and perform normal tidal breathing. The patients needed to have a previous record of $P$. aeruginosa in their sputum. The results showed a $10 \%$ increase in $\mathrm{FEV}_{1}$ at week 20 and a mean decrease in sputum $P$. aeruginosa density of $0.8 \log _{10}$ colony-forming units. The adverse effects recorded were tinnitus and voice alteration, but these were not severe enough to warrant cessation of aerosol administration. 


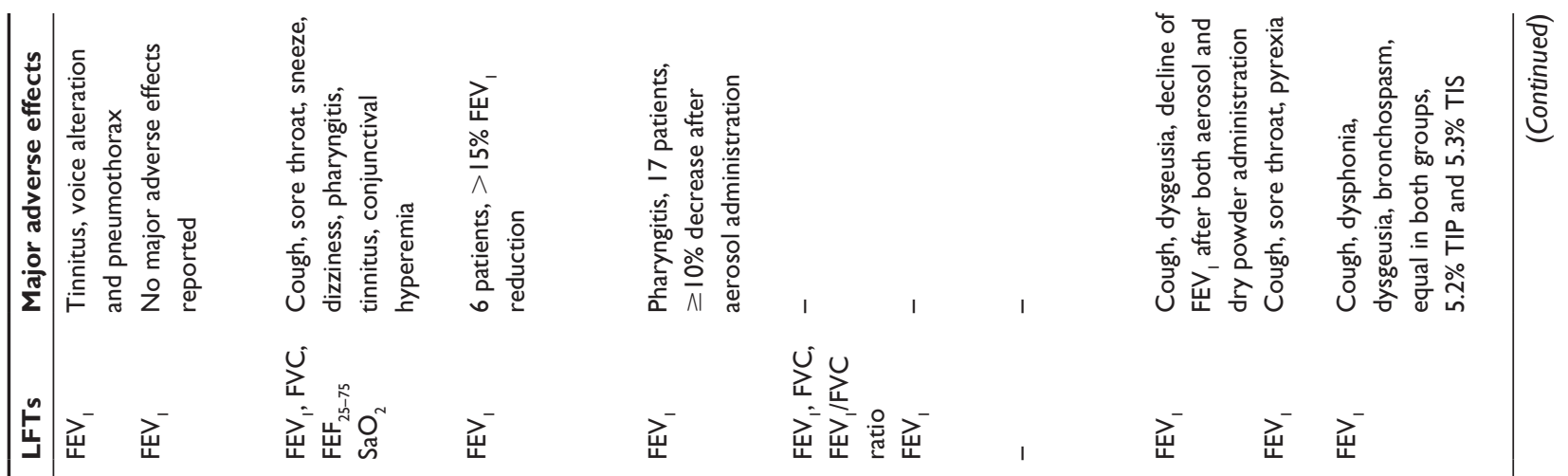

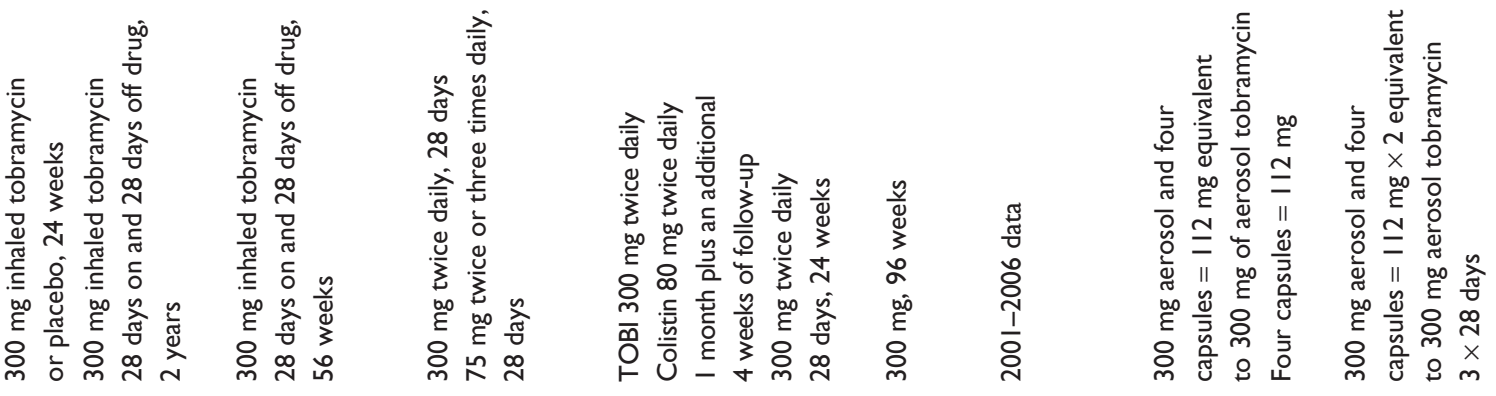

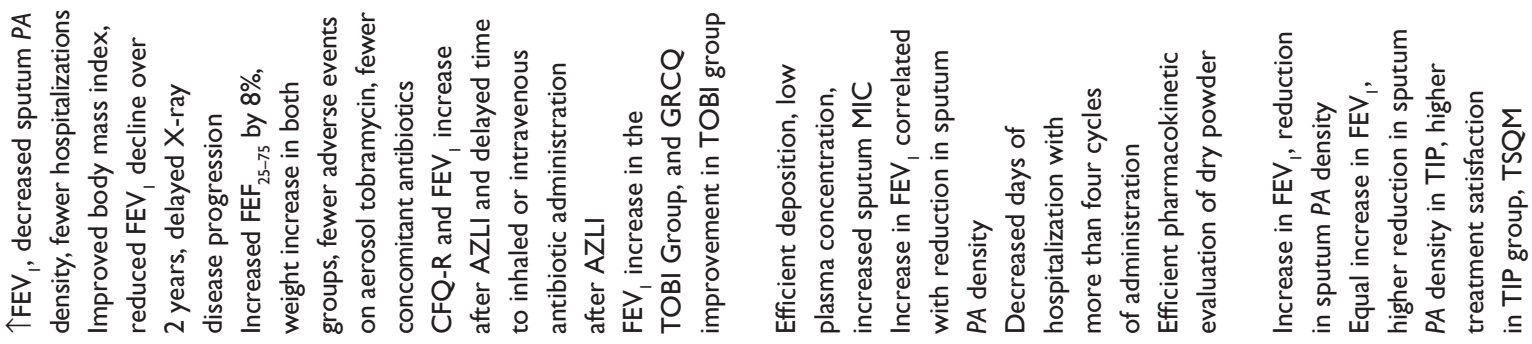

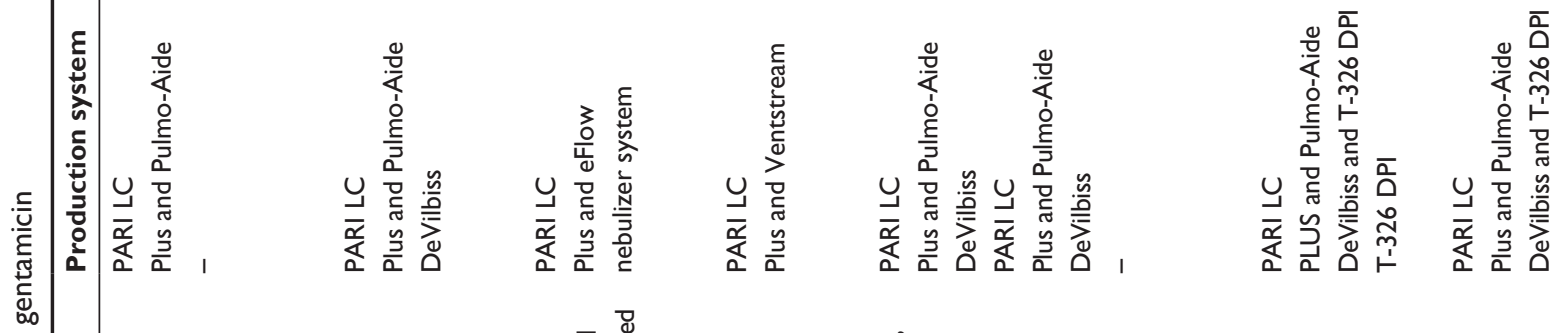

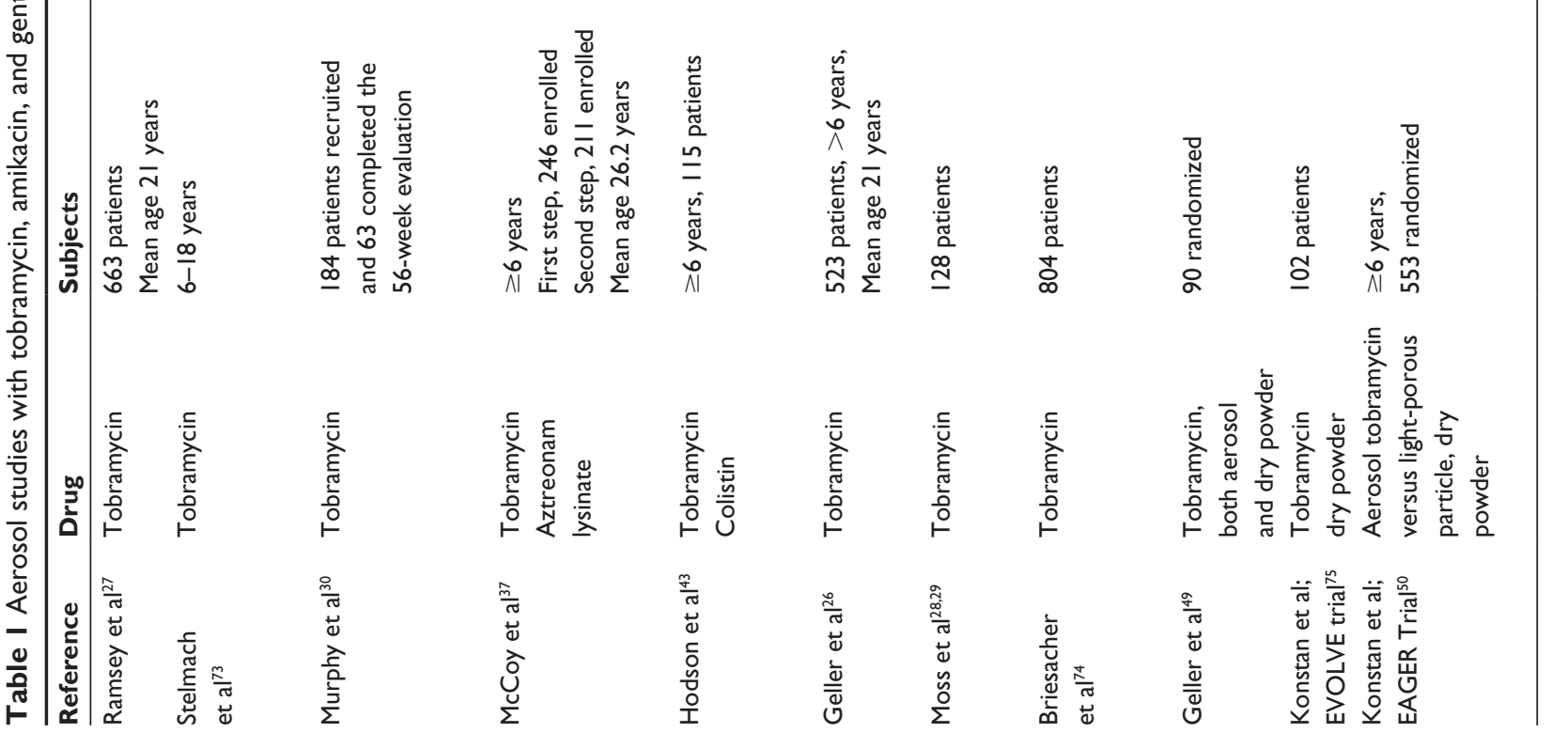




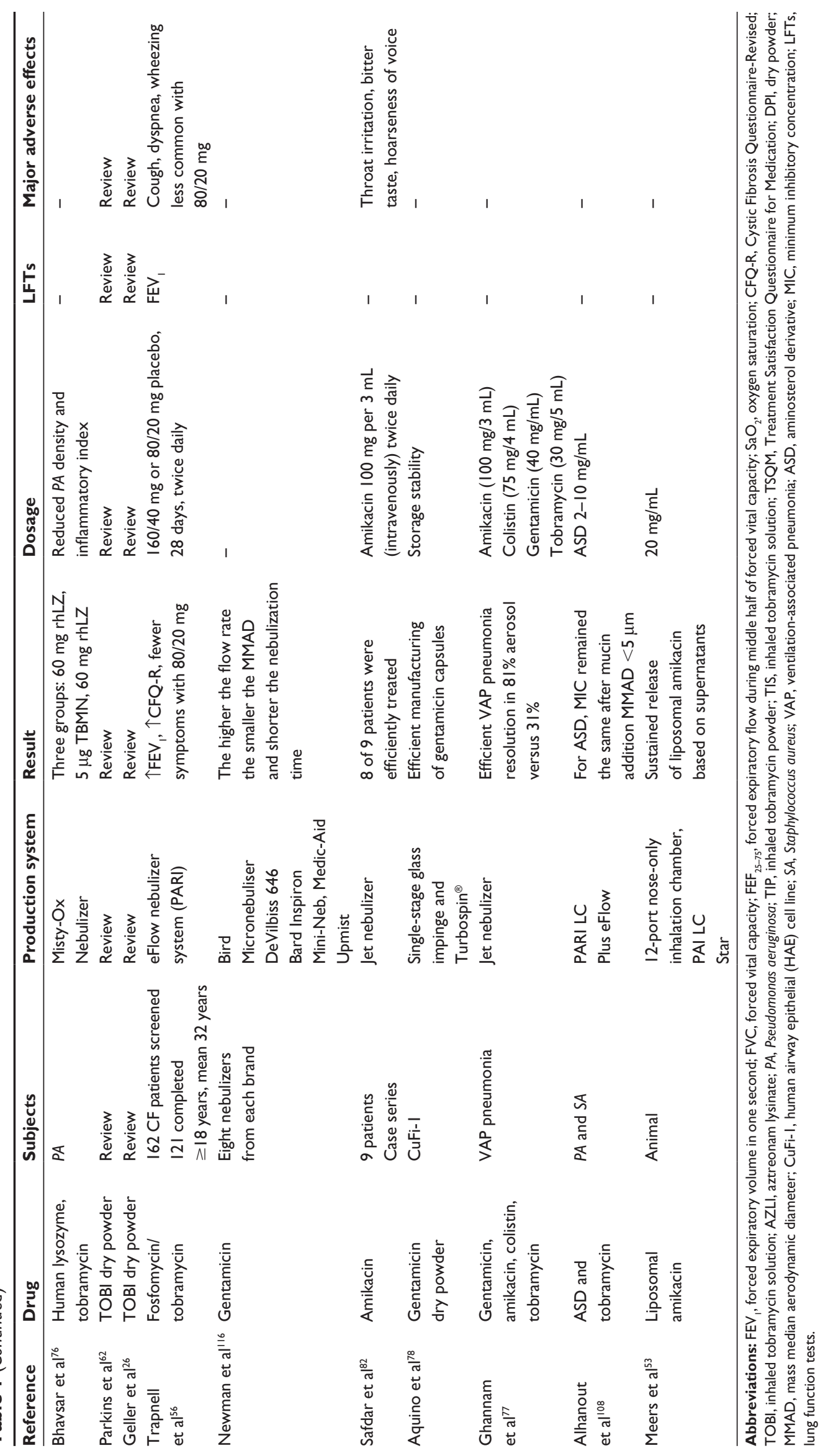


Pneumothorax was observed in one patient. Most importantly, fewer hospitalizations were observed in the group receiving aerosolized tobramycin. ${ }^{27}$ Another small uncontrolled study in 12 patients recorded height, weight, chest X-ray (Brasfield score) and $\mathrm{FEV}_{1}$. After 2 years of administration of inhaled tobramycin $300 \mathrm{mg}$ twice daily (28 days on and 28 days off), the decline in $\mathrm{FEV}_{1}(\Delta)$ decreased, body mass index increased, and radiologic disease progression was again decreased. ${ }^{73}$

In a study by Murphy et al, ${ }^{30} 184$ patients were enrolled to receive aerosolized tobramycin $300 \mathrm{mg}$ twice daily administered with the LC Plus jet nebulizer and a PulmoAide compressor for 56 weeks. Again, administration was performed on a 28-day on and 28-day off cycle. Respiratory functions were recorded, and this study presented additional data regarding forced vital capacity (FVC) and forced expiratory flow during the middle half of forced vital capacity $\left(\mathrm{FEF}_{25-75}\right)$. The most important observation was an $8 \%$ increase in $\mathrm{FEF}_{25-75}$ (an index of small airways function) in the aerosolized tobramycin group. Moreover, fewer hospital admissions and fewer days of hospitalization were observed in the group receiving aerosolized tobramycin. Concomitant antibiotics were administered to fewer patients receiving aerosolized antibiotics (102 days versus 124 days in the control group). Further, both groups showed an increase in body weight, and no severe adverse effects were observed. However, two patients were withdrawn from the study because of severe cough, sneezing, and sore throat related to administration of the aerosol. Hoarseness of voice was also observed in almost all patients receiving aerosolized tobramycin.

The pharmacokinetics of tobramycin were assessed in a 24-week study by Geller et al. ${ }^{26}$ The main observation was that aerosol deposition was not associated with changes in pulmonary function tests, ie, $\mathrm{FEV}_{1}, \mathrm{FVC}$, and $\mathrm{FEV}_{1} / \mathrm{FVC}$, as would be expected. It has always been a point of debate whether underlying respiratory disease influences deposition of the aerosol. However, more information is necessary regarding the site of sample collection, ie, from the central or distal airways. Another major point was the low plasma drug concentration and local increase in sputum concentration. The methodology used in this study provides an excellent example of the pharmacokinetic superiority of a local treatment modality. ${ }^{48}$

In a study by Moss et al, ${ }^{28}$ a reduction in sputum P. aeruginosa density was associated for the first time with an increase in $\mathrm{FEV}_{1}$. Again, weight gain, increase in $\mathrm{FEV}_{1}$, and reduction in sputum $P$. aeruginosa density were observed in this long-term 96-week study. Evaluation of nephrotoxicity and ototoxicity also indicated no adverse effects other than tinnitus; however, neither of the two patients affected had to discontinue administration of the drug. Patient adherence with tobramycin was associated with cost-effectiveness of therapy and days of hospitalization. It was observed that 804 patients receiving more than four cycles of tobramycin per year (2001-2006 data) had a significant reduction in hospitalization and fewer outpatient service costs. However, higher outpatient prescription drug costs were recorded. ${ }^{74}$ Tobramycin was evaluated as an aerosol versus a dry powder. Pharmacokinetics were assessed, and major observations were made regarding future development of antibiotic formulations. First, the timing of administration was significantly reduced compared with the 15 minutes required for nebulization. For the first time, the plasma concentration of tobramycin was evaluated until 12 hours after administration. The time taken to reach peak plasma concentration was one hour after administration for both the aerosol and the dry powder. In addition, the area under the curve and peak plasma concentration were detected between subjects receiving $4 \times 14 \mathrm{mg}$ and $2 \times 28 \mathrm{mg}$ capsules. Moreover, systemic exposure was identical for the $300 \mathrm{mg}$ aerosol and the $112 \mathrm{mg}$ dry powder. One patient had to discontinue administration of the dry powder because of severe cough. However, there was a difference in the decrease in $\mathrm{FEV}_{1}$ of $10 \%-20 \%$ between the aerosol and dry powder formulations. Only one patient had a decrease in $\mathrm{FEV}_{1}$ of $20 \%$ and had to discontinue treatment. This study provides valuable data indicating that this new methodology for antibiotic administration should be pursued at least for cystic fibrosis and in patients with respiratory function appropriate for dry powder usage. ${ }^{49}$ The safety and efficacy of the dry powder formulation of tobramycin was evaluated in the EVOLVE (Tobramycin Inhalation Powder [TIP] for P. aeruginosa Infection in Cystic Fibrosis Subjects) trial. The maximum administration time was 4-6 minutes. The major adverse effects occurring in both the tobramycin and placebo dry powder inhaler groups were cough, sore throat, and pyrexia; however, pyrexia was only related to the dry powder. Again, $\mathrm{FEV}_{1}$ was increased in the dry powder inhaler group and sputum $P$. aeruginosa density was decreased; this observation was confirmed again when placebo patients were switched to tobramycin by dry powder inhaler. ${ }^{75}$

In the EAGER (Safety, efficacy and convenience of tobramycin inhalation powder in cystic fibrosis patients) trial, ${ }^{50}$ inhalation dry powder was evaluated versus inhalation solution. The increase in $\mathrm{FEV}_{1}$ was equal for the two groups at all times of spirometric evaluation. The sputum 
$P$. aeruginosa density was observed to be lower in the inhalation dry powder group during the 28 days of cycle 3 . Adverse effects and in particular cough were observed to be more severe in the inhalation dry powder group. This finding is attributable to the fact that the dry powder fibers have the one axis increased, so the particles have a linear shape which irritates the respiratory tract epithelium and provokes cough. Information on this issue is not available for this study. Cough was diminished after several administrations of treatment; however, $4 \%$ of patients (12/308) in the inhalation dry powder group discontinued treatment in comparison with $1 \%$ of patients $(2 / 209)$ in the inhalation solution group. Bronchospasm (defined as a $>20 \%$ reduction in $\mathrm{FEV}_{1}$ ) after administration was observed to be the same in both groups $(5.2 \%$ inhalation dry powder versus $5.3 \%$ inhalation solution). Hearing complaints tended to be intermittent and transient in both groups $(0.97 \%$ inhalation dry powder versus $0.96 \%$ inhalation solution). The minimum inhibitory concentration (MIC) of tobramycin dry powder was increased on day 28 of cycle 3 in both groups. Finally, it should be mentioned that there were significantly more patients requiring new antipseudomonal antibiotics in the inhalation dry powder group than in the inhalation solution group. ${ }^{62}$ Greater adherence and satisfaction with treatment were recorded on the Treatment Satisfaction Questionnaire for Medication in the inhalation dry powder group, with a mean administration time of 5.6 minutes versus 19.7 minutes for the inhalation solution group (ie, higher than previously observed $^{75}$ ).

In an effort to investigate possible enhancement of tobramycin aerosol administration, human lysozyme was coadministered with tobramycin. It was observed by measuring bronchoalveolar lavage fluid, neutrophils, and lung histopathology samples that human lysozyme had antiinflammatory properties and enhanced the antibacterial effect of tobramycin. ${ }^{76}$ Four different antibiotics were administered in the trial by Ghannam et al; ${ }^{77}$ three of these were prepared from intravenous solutions and were administered in cancer patients with ventilation-associated pneumonia. It was observed that, in comparison with intravenous administration, aerosol administration did not induce renal toxicity and that the ventilation-associated pneumonia resolution rate was $81 \%$ in comparison with $31 \%$ for intravenous administration (Table 1).

\section{Aztreonam lysinate}

The efficiency of an aztreonam lysinate aerosol antibiotic formulation was evaluated in a dose-escalation study. Forty patients were enrolled, including 21 adults and 19 adolescents. The drug formulation was administered using an eFlow nebulizer system; the mass median diameter of the droplets was $3.6 \pm 0.1 \mu \mathrm{m}$ and the geometric standard deviation was $1.6 \pm 0.1 \mu \mathrm{m}$. The patients were divided into a dose-escalation group (75 mg-150 mg-225 mg) and a placebo group. Pulmonary function tests, ie, FVC, $\mathrm{FEV}_{1}$, and $\mathrm{FEF}_{25-75}$, were evaluated by spirometry. The total study period was 13 days and the administration was performed in a 3-day manner. Only one adolescent patient showed a $>20 \%$ decrease in $\mathrm{FEV}_{1}$, and the maximum tolerated dose was established at $75 \mathrm{mg}$. However, for adults, no decrease $\geq 20 \% \mathrm{FEV}_{1}$ was observed in order for the maximum tolerated dose to be determined. The spirometry examination was performed three times, once before aerosol administration, and then 30 minutes and 2 hours after aerosol administration in order to cover all scenarios from early to late airway hyperresponsiveness. Adverse events were recorded using the MedDRA (Medtra (S) Pte Ltd, Singapore) 5.0 classification system. The usual adverse effects were observed, ie, chest tightness, nasal congestion, aggravated cough, and increased sputum, which is expected to be increased when a saline solution is administered. There was a trend towards a numeric increase in adverse effects with an increase in dosage for the adults but not for the adolescents. Again, only one patient had to stop the treatment when the maximum tolerated dose was reached at $75 \mathrm{mg}$. A very important aspect of this study was the plasma concentration of the drug, which was measurable at one hour and still detectable after 8 hours, indicating sustained drug absorption from the lung parenchyma into the circulation, as previously observed in other studies. ${ }^{23}$ Additionally, drug concentrations were measurable in the sputum of patients after 10 minutes, and were still detectable 2 and 4 hours after aerosol administration. This study provides excellent information regarding the pharmacokinetics of the aztreonam lysinate aerosol and a methodology via which to evaluate aerosol antibiotics.

The pharmacokinetics of aztreonam lysinate $75 \mathrm{mg}$ and $225 \mathrm{mg}$ were evaluated further in a study of 105 patients by Retsch-Bogart et al. ${ }^{35}$ Positive results regarding pulmonary function tests were observed after 7 days, and sputum P. aeruginosa density also decreased significantly. The plasma drug levels reached were dose-dependent, as was the sputum aztreonam lysinate concentration. There were no severe adverse effects in any of the patients. This study provides importance evidence regarding a bronchoconstrictive effect that has not been observed before. Specifically, there were patients were they had their $\mathrm{FEV}_{1}$ decreased more than $30 \%$ 
after the aerosol administration and a careful follow-up of 2 hours with spirometry indicating that the pulmonary function returned for these patients to $15 \%$ of pretreatment values. However, a similar effect was observed for a patient in the placebo group. Similar adverse effects have been observed with other inhaled therapies, and it is not yet clear whether this is due to the concentration of the drug, its chemical structure, or a background of hyperresponsiveness. ${ }^{23,68}$ In any case, all these factors play an important role in bronchoconstriction. In addition, patients administered short-acting bronchodilators before treatment had a lower decrease in $\mathrm{FEV}_{1}$. Administration of aztreonam lysinate $75 \mathrm{mg}$ was again evaluated in a 28-day trial. The CFQ-R score was the primary endpoint and the FEV increase was the second endpoint. Indeed, an increase in both values was observed, and although decreased after discontinuation of aztreonam lysinate, still remained increased compared with baseline values. Sputum and plasma drug concentrations were again dose-related. A decrease $\geq 15 \%$ was again observed after each inhalation of aztreonam lysinate, with a short-acting bronchodilator administered 15 minutes beforehand. ${ }^{36}$ Similar results were also observed in a study by Wainwright et al, ${ }^{40}$ who clearly stated for the first time that aerosol therapy is contraindicated when atelectasis and pleural effusion are present. This has also been shown for other aerosol treatment modalities. ${ }^{19,24}$ In a study by Oermann et al, ${ }^{38}$ the $75 \mathrm{mg}$ aztreonam lysinate formulation was administered for 18 months either twice daily or three times daily. Pulmonary function tests, CFQ-R scores, and weight were increased in the three times daily group; however, adverse respiratory effects were observed in 50 patients, and adherence was observed to be slightly lower $(4 \%)$ in the three times daily group. In any case, better results were observed in the three times daily group. There were fewer hospitalizations and a lower $P$. aeruginosa density in sputum samples. This was an excellent long-term study presenting the different aspects of administration methodology that can be used and how these influence different aspects of the patient's clinical situation.

A combination of tobramycin and aztreonam lysinate was administered in a multicenter study in which patients first received tobramycin for 28 days followed by aztreonam lysinate for 28 days. The major positive outcome other than increased $\mathrm{FEV}_{1}$, improvement on $\mathrm{CFQ}-\mathrm{R}$, and reduced sputum $P$. aeruginosa density, was that patients receiving aztreonam lysinate had a delayed time to receiving inhaled or intravenous antibiotics. ${ }^{37}$ Moreover, $\mathrm{a} \geq 15 \%$ reduction in $\mathrm{FEV}_{1}$ was observed in six patients. In a publication following this study, the susceptibility of $P$. aeruginosa was investigated. Sputum samples were obtained from all patients, and a 30\% increase in MIC, a few decreases in $P$. aeruginosa susceptibility to other antibiotics, and an increase in tobramycin susceptibility was observed $^{39}$ (Table 2).

\section{Gentamicin}

Gentamicin solution was nebulized by 32 nebulizers representing four different brands (Bird Micronebulizer ${ }^{\circledR}$, Bird Corporation, Palm Springs, CA, USA; DeVilbiss 646; Inspiron Mini-Neb ${ }^{\circledR}$, CR Bard Inc, Covington GA, USA; and Upmist $^{\circledR}$, Medic-Aid Limited, Bognor Regis, UK). It was observed that the higher the flow rate, the smaller the droplet mass median aerodynamic diameter (MMAD) produced and the shorter the nebulization time. Moreover, the higher the loading in the residual cup, the smaller the MMAD. In addition, the methodology of adding $\mathrm{NaCl} 0.9 \%$ to the residual cup when the concentration was reduced to half of the initial dosage was proposed in order to produce further small droplets $<5 \mu \mathrm{m}$ during aerosol administration. Using this method more than once does not have any additional benefit because the concentration of drug is reduced. Gentamicin has also been investigated as a dry powder formulation with leucine. Leucine was observed to improve the properties of the dry powder formulation of gentamicin. The safety of the formulation was evaluated in CuFi-1 cells, and no adverse effects were observed 24 hours after administration. Leucine improved the dispersibility of the aerosol and modified the surface of the particles. The formulation was stable after 6 months of storage. A new gentamicin alginate microparticle has recently been developed, but needs to be investigated further as an aerosol formulation ${ }^{78}$ (Table 1).

\section{Colistin}

Aerosolized colistin and tobramycin were administered in a randomized clinical study including 115 patients for one month, with an additional 4 weeks of follow-up to compare the safety and effectiveness of the two drugs. ${ }^{43}$ Fewer adverse airway reactivity effects were observed in the tobramycin solution group $(n=6)$ than in the colistin group $(n=11)$. There was also an increase in $\mathrm{FEV}_{1}$ in the tobramycin group, especially in younger patients. However, both groups showed a decrease in sputum $P$. aeruginosa density, with no difference observed between groups in this regard. FVC was also recorded, but no data regarding changes in FVC were reported because this was not a primary endpoint. The medical condition of the patients was also evaluated using the Global Rating of Change questionnaire, ${ }^{43}$ and it was observed that patients receiving tobramycin benefited more. In another study by Jensen et al, ${ }^{42}$ colistin was administered for 3 months versus placebo. A different aerosol 


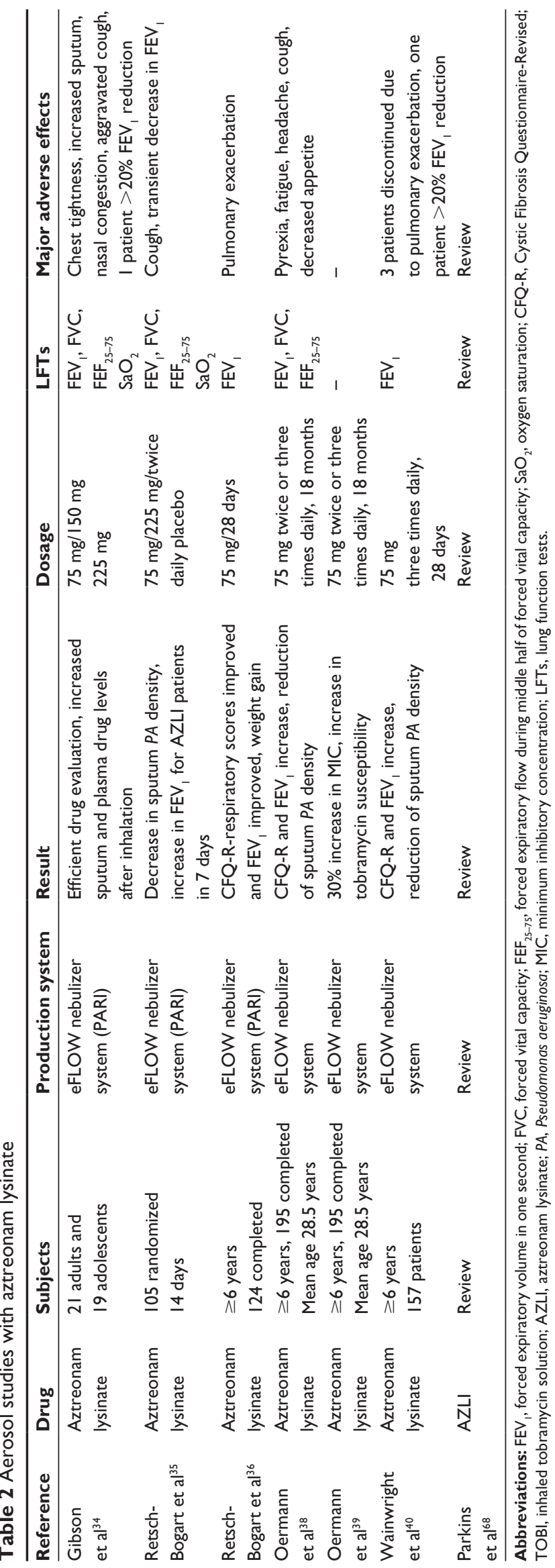

production system was used, ie, the Raindrop ${ }^{\circledR}$ (Purian-Bennett Corporation, Overland Park, KS, USA) nebulizing chamber which nebulizes $3 \mathrm{~mL}$ in 15 minutes. The decrease in $\mathrm{FEV}_{1}$ and FVC over the 3-month period was lower in the colistin group, and inflammatory markers such as white cell count and erythrocyte sedimentation rate were also marginally decreased. Sputum $P$. aeruginosa density was also decreased. However, adverse effects, including severe irritating cough and burning sensation on the tongue, were severe enough in three patients to require withdrawal from the study. At this point, we should report a case of hypersensitivity pneumonitis due to high-dose colistin therapy where the patient had to be intubated. The treatment was stopped after 12 days, and the eosinophil count normalized after 3 days. The patient was efficiently weaned to pressure support mode with minimal pressure support. ${ }^{79}$

Colistin has been administered as an aerosol in ventilated-associated pneumonia caused by $P$. aeruginosa and Acinetobacter baumannii using an Aeroneb Pro vibrating plate nebulizer (Serogen, Galway, Ireland). The major concern regarding aerosol production was the strict coordination needed on the part of the patient, and therefore additional propofol administration was necessary. Eliminating inspiratory turbulence was necessary for efficient aerosol deposition. ${ }^{80}$ Pharmacokinetics were also evaluated using blood samples, and it was observed that the colistin concentration was higher on day 3 than on day 2, with no significant difference in this regard between the groups receiving aerosolized colistin with and without additional intravenous antibiotics. Moreover, no airway clearance side effects were observed between the groups. The study by $\mathrm{Lu}$ et a ${ }^{81}$ was one of the first to evaluate aerosol efficiency using computed tomography. Efficiency was observed for both sensitive and resistant strains. The MIC was increased in only two patients (Table 3).

\section{Amikacin}

The pharmacokinetics of aerosolized liposomal amikacin was evaluated in a rat model and sputum samples from cystic fibrosis patients in comparison with an aerosolized tobramycin formulation. First, it was observed that liposomal amikacin had a sustained release effect locally and in the systemic circulation. One administration was enough for liposomal amikacin levels to be detectable after 3 days. Blood levels detected were 8 (lungs) $>2$ (kidneys), indicating that local administration enables slow release in the systemic circulation, providing enough time for efficient and safe clearance of the drug. The same concept can be applied to other experimental treatment modalities where large concentrations are 


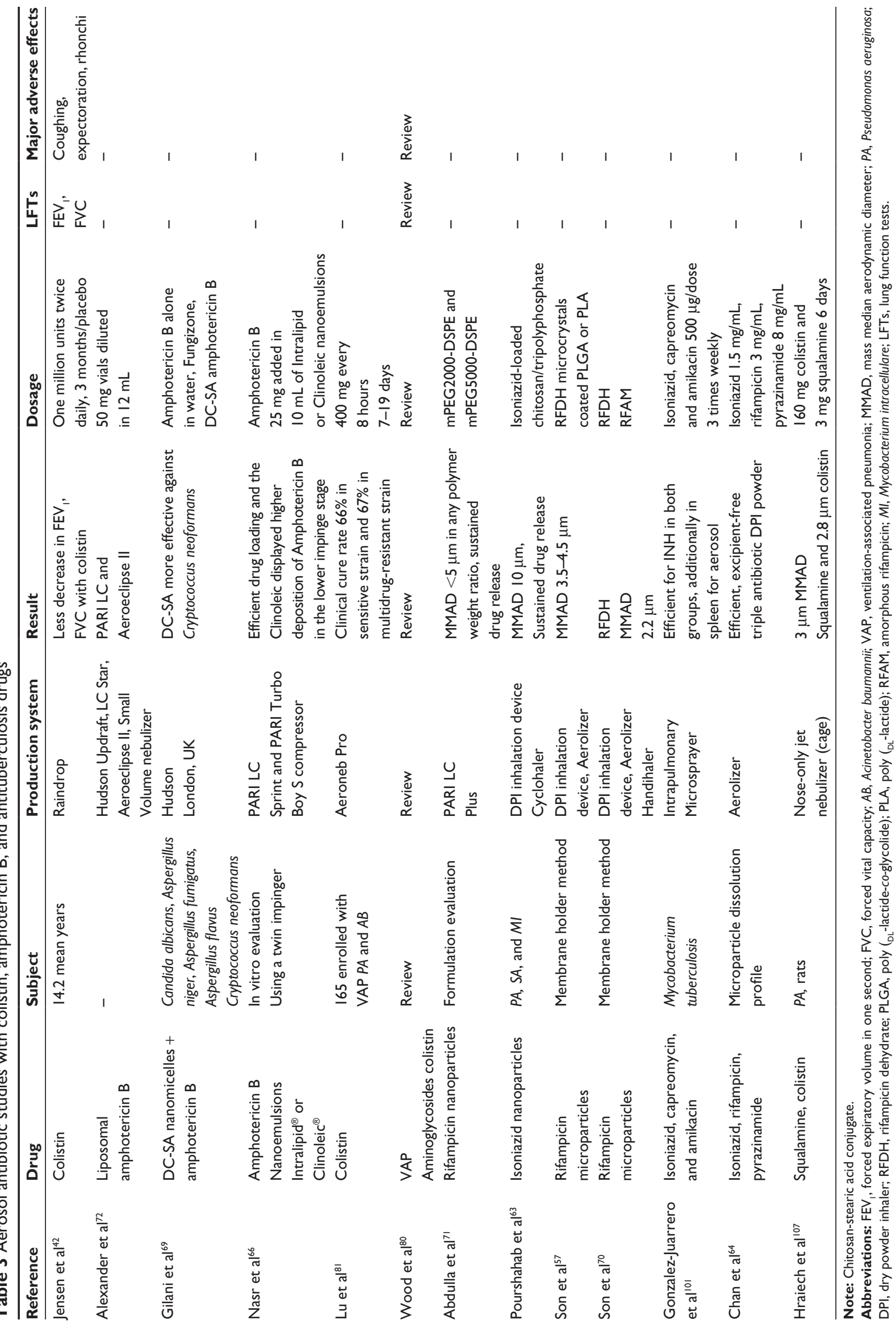


needed to reach the target tissue; however, during metabolism of the same concentration in another tissue, such as the liver or kidney, the same concentration may be toxic. In several situations where administering a drug intravenously unnecessarily exposes healthy cells and organs to toxicity, by the time the drug reaches its target tissue, a large concentration of toxic metabolites has already caused damage to normal tissue. The sustained-release effect is associated with the concentration of rhamnolipids, ie, the monorhamnolipid and dirhamnolipid found in $P$. aeruginosa biofilm which are responsible for release of the amikacin contained in the liposomes. One rhamnolipid molecule is enough for extraction of 100 liposomal amikacin molecules. Additional observations were made regarding penetration of the formulation into sputum from patients with cystic fibrosis. The formulation efficiently penetrated the mucus independent of the size of the liposomes, and it was observed that the liposomes had the ability to modify while penetrating the mucus. Thick mucus is a major problem in patients with cystic fibrosis, and the liposomal formulation demonstrated superiority in comparison with aerosolized tobramycin with regard to penetration of this thick mucus. Reduction of sputum P. aeruginosa density was greater in comparison with that achieved using aerosol tobramycin in this study, and bacteria were undetectable after administration of liposomal amikacin in several animals. Penetration of liposomal amikacin was also observed to be higher at the site of infection and subsequently at the site where the $P$. aeruginosa population was highest within sputum. Finally, it was observed that alternate day dosing of the formulation is an efficient method of administration for this type of formulation. This is an excellent study showing all aspects of the pharmacokinetics of liposomal carriers, and this method of encapsulation and drug release has been pursued in other experimental studies. However, the local trigger for drug release in the respiratory epithelium has not been identified. An intravenous solution of amikacin ( $50 \mathrm{mg}$ per $3 \mathrm{~mL}$ ) was administered twice daily as an aerosol to nine patients with nontuberculous immunosuppression. Adverse effects were self-limiting and not severe enough to warrant withdrawal from the study. Of the nine study participants, eight responded to the treatment and one died from underlying disease. This study shows favorable data indicating this intravenous solution can be aerosolized efficiently as an effective treatment for patients who are otherwise difficult to treat. ${ }^{82}$

\section{Levofloxacin}

Aerosolized levofloxacin (300 mg) is being investigated under the name MP-376. This novel formulation, apart from demonstrating efficient control of bacteria, has been shown to have additional immunomodulatory and anti-inflammatory properties. In a study by Tsivkovskii et al using human BE135 bronchial epithelial cells, ${ }^{83} \mathrm{MP}-376$ decreased production of interleukin-6 and interleukin-8, whereas tobramycin aerosol solution increased production of interleukin-6. Aerosolized levofloxacin needs to offer additional benefits, as do the macrolides. ${ }^{84}$ Further investigation of this agent was performed in comparison with amikacin, ciprofloxacin, tobramycin, and aztreonam against $P$. aeruginosa, Burkholderia cepacia complex, Stenotrophomonas maltophilia, Alcaligenes xylosoxidans, and Staphylococcus aureus. The two quinolones demonstrated the highest activity against the Gram-negative pathogens seen in cystic fibrosis. Levofloxacin demonstrated higher potency against methicillin-sensitive $S$. aureus and methicillin-resistant $S$. aureus, while aztreonam was not active against methicillinsensitive $S$. aureus or methicillin-resistant $S$. aureus. The bacterial activity of levofloxacin was observed to be more rapid and complete when compared with that of tobramycin and aztreonam (30 minutes for 11/12 isolates tested). Tobramycin killed $58 \%$ of isolates in 30 minutes and aztreonam was the slowest of the three agents. The antibacterial activity of levofloxacin was the same for mucoid and nonmucoid $P$. aeruginosa isolates. In conclusion, levofloxacin was the most potent antibiotic against cystic fibrosis isolates, with an $\mathrm{MIC}_{90}$ in the range of 8-32 $\mu \mathrm{g} / \mathrm{mL}$. The quinolones, ciprofloxacin and levofloxacin, had a protective effect against inhaled Bacillus anthracis, Yersinia pestis, and Francisella tularensis when administered subcutaneously or intraperitoneally at a dose of 90-120 mg/ $\mathrm{kg}$ /day. ${ }^{85}$ Liposomal nanoparticles containing ciprofloxacin were investigated as an aerosol. The aerosol formulation was produced with a LC Sprint ${ }^{\circledR}$ and Turbo Boy S compressor ${ }^{\circledR}$ (PARI Pharma GmbH), and was administered to Calu-3 bronchial epithelial cells, with observation of efficiency against $P$. aeruginosa and $S$. aureus. The MMAD was $3.6 \mu \mathrm{m}$ and the geometric standard deviation was 2.3. The aerosol nanoformulation was stable during storage and nebulization, and showed sustained-release properties. However, drug release was slower in comparison with the previously discussed studies due to the fact that several parameters were absent in the in vitro evaluation model (eg, macrophages, mucociliary clearance, and virulence factors). ${ }^{53}$ Moreover, the formulation was not effective against S. aureus, which was attributed to the thick peptidoglycan cell wall. However, as previously observed, these liposomes tend to modify their properties while interacting with mucus, ${ }^{53}$ so further investigation of this formulation is warranted in an in vivo model and sputum solution. Superiority of levofloxacin was observed in comparison with tobramycin, amikacin, and 
aztreonam when administered to $114 P$. aeruginosa isolates in an hypoxia-induced model. All antibiotics except levofloxacin showed an increase in geometric mean values for MIC (tobramycin seven-fold, amikacin four-fold, and aztreonam six-fold), whereas the MIC for levofloxacin was increased by only two-fold in an anaerobic environment. The $\mathrm{MIC}_{50}$ was increased four-fold for tobramycin and 16-fold for aztreonam. Forty percent of the isolates showed an MIC increase of more than four-fold for tobramycin, amikacin, and aztreonam, but of only $4 \%$ for levofloxacin ${ }^{55}$ (Table 4 ).

\section{Clarithromycin}

Clarithromycin was investigated as an aerosol versus an oral agent in a rat model. Safety was also evaluated. Blood samples and bronchoalveolar lavage were used to determine these parameters. The blood clarithromycin concentration was lower in the aerosol group, and drug concentration was observed in epithelial lung fluid and alveolar macrophages. The structure of the alveoli and mechanisms of transportation from the alveoli to the blood circulation and inverse are well known, ie, the capillary lumen, connective tissue, and alveolar epithelial cells. ${ }^{86}$ The capillary lumen acts as a filter via which the solution enters the systemic circulation. In addition, local transporters, ie, the MDR1/P-glycoprotein substrate, play a major role in transporting drug molecules from the alveolar region to the blood circulation, and the inverse. ${ }^{87-91}$ It has been observed that it is easier for a molecule to be transported from the alveolus to the circulation than the inverse. ${ }^{91}$ Therefore, at least for the clarithromycin aerosol formulation, it has been demonstrated that systemic side effects are fewer because less drug is introduced into the systemic circulation. In the current study, the safety of the formulation was demonstrated, given that no release of lactate dehydrogenase from lung tissue was observed. Further, the concentration of the aerosol clarithromycin formulation was observed to be 29-fold higher in alveolar macrophages than in epithelial lung fluid. Finally, the clarithromycin aerosol was observed to be stable in alveolar macrophages and epithelial lung fluid for 48 hours after administration, regardless of biodegradable molecules existing within epithelial lung fluid and alveolar macrophages $^{92-96}$ (Table 4).

\section{Amphotericin B}

Four different nebulizers were evaluated as to whether they could produce droplets with an MMAD size $<5 \mu \mathrm{m}$, which is necessary in order for the aerosol to be deposited in the distal airways. The Hudson Updraft ${ }^{\circledR}$ (Hudson Respiratory Care, Temecula, CA, USA), LC Star ${ }^{\circledR}$ (PARI Respiratory
Equipment, Midlothian, VA, USA), Small Volume Nebulizer ${ }^{\circledR}$ (eValueMed, Mexico), and Aeroeclipse II $^{\circledR}$ (Monaghan Medical Corporation, Plattsburgh, NY, USA) were driven by compressed air at a flow rate of $8 \mathrm{~L}$ per minute. The PARI LC and Aeroeclipse II were the best nebulizers for producing an optimal droplet size for efficient lung deposition. ${ }^{72}$ Amphotericin B was compared after modification involving encapsulation in chitosan-stearic acid conjugate nanomicelles with a commercially available formulation of amphotericin B. These formulations were tested against five different fungal organisms, ie, Candida albicans, Aspergillus niger, Aspergillus fumigatus, Aspergillus flavus, and Cryptococcus neoformans. It was observed that amphotericin B encapsulated in chitosan-stearic acid conjugate micelles was more effective than the commercially available formulation of amphotericin B for inhibition of the growth of $C$. neoformans. Further investigation of this method of encapsulation is warranted in an in vivo model for reasons as previously explained. ${ }^{69}$ Moreover, in another study, amphotericin B was incorporated into three different cholesteryl carbonate esters, ie, sodium cholesteryl carbonate, dicholesteryl carbonate, and cholesteryl palmitate. The dry powders produced were observed to be stable after 3 months of storage, and the MMAD was measured to be $6.8-8 \mu \mathrm{m}$. The powder was effective against C. neoformans and C. albicans, and further investigation of this form of encapsulation is warranted. ${ }^{65}$ In a study by Nasr et al, ${ }^{66}$ a lipid nanoemulsion containing amphotericin $\mathrm{B}$ aerosol was evaluated. The amphotericin B (25 mg) was prepared either with Intralipid ${ }^{\circledR}$ (Fresenius Kabi AB Uppsala, Sweden) or Clinoleic ${ }^{\circledR}$ (10 mL, Clintec Parenteral, Maurepas, France) and aerosolized with a PARI Sprint jet nebulizer. An in vitro evaluation was performed using a twin impinger. The nanoemulsion prepared with Clinoleic showed deposition at the lower impinging stage ( $80 \%$ versus $57 \%$ for Intralipid) and therefore would be theoretically more efficient in an in vivo evaluation model (Table 3 ).

\section{Rifampicin}

The antituberculosis drug, rifampicin, was investigated when encapsulated in poly-(ethylene oxide)-block-distearoyl phosphatidyl-ethanolamine polymers of two different molecular weights (mPEG2000-DSPE and mPEG5000-DSPE). The two formulations were nebulized efficiently using a jet nebulizer and the particle size range was $162-395 \mathrm{~nm}$. The MMAD was identified as being $2.6 \mu \mathrm{m}$, and the aerodynamic characteristics were not influenced by the molecular weight of the copolymers. Encapsulation efficiency was also unaffected by the molecular weight of the copolymer and the 


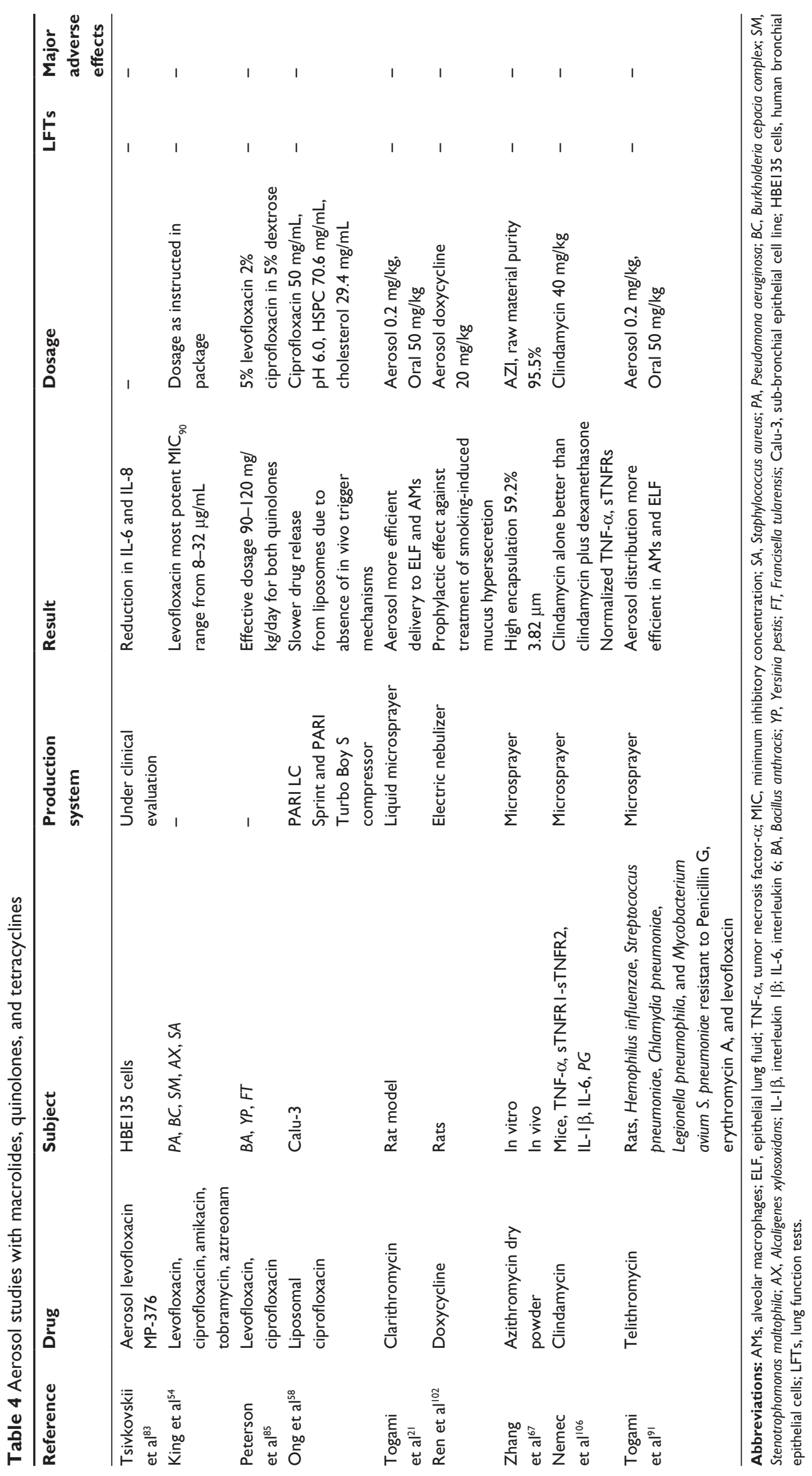


highest encapsulation efficiency was observed when the drug/ copolymer ratio was 1:5. Sustained release was observed for up to 3 days, and the mPEG2000-DSPE formulation were observed to be larger in size than the mPEG5000-DSPE. The size decreased when the PEG content in the formulation was increased. It should be mentioned that the PEG molecule adds a "stealth" ability, which enables the formulation to go unrecognized by the defense mechanisms of the respiratory tract, such as tracheal and alveolar macrophages ${ }^{97}$ The PEG molecule has also been observed to be safe on aerosol administration..$^{98}$ Finally, these formulations are excellent carriers, and further evaluation in an in vivo model is warranted. Microencapsulation of rifampicin was investigated when rifampicin dehydrate was coated with poly $\left({ }_{\mathrm{DL}}\right.$-lactideco-glycolide) or poly ( ${ }_{\mathrm{DL}}$-lactide). The MMAD range produced for all the formulations was 3.6-4.5 $\mu \mathrm{m}$. The uncoated formulation showed immediate drug release followed by sustained release for 8 hours. The slowest drug release was observed from the poly $\left({ }_{\mathrm{DL}}\right.$-lactide) formulation. The major observation was the effect of low $\mathrm{pH}$ as a drug release trigger for the poly $\left({ }_{\mathrm{DL}}\right.$-lactide) carriers in comparison with the uncoated formulation. ${ }^{70}$ The $\mathrm{pH}$ of the environment has been previously identified as a trigger for release of drug in several formulations. ${ }^{99}$ In conclusion, based on the target tissue and organ (eg, gastric route), this formulation can be modulated to be an efficient treatment.

Rifampicin dehydrate was further investigated by recrystallization of rifampicin in anhydrous ethanol (rifampicin dehydrate) versus amorphous rifampicin with two dry powder inhalers, ie, the Aerolizer ${ }^{\circledR}$ (Merck, Whitehouse Station, NJ, USA) and Handihaler ${ }^{\circledR}$ (Boehringer Ingelheim, Ingelheim, Germany). The Aerolizer was found to be superior to the Handihaler, producing a MMAD of $2.2 \mu \mathrm{m}$. Stable storage was observed for 9 months, along with reduced agglomeration in the rifampicin dehydrate formulation in contrast with the amorphous rifampicin formulation. Maximum potency delivery was observed with the rifampicin dehydrate formulation. ${ }^{57}$ In another study investigating dry powders, an excipient-free triple antibiotic (isoniazid, pyrazinamide and rifampicin) dry powder was produced with a MMAD of $3.5 \pm 0.1 \mu \mathrm{m}$. This formulation has to be further tested in an in vivo model ${ }^{64}$ (Table 3).

\section{Isoniazid}

Further investigation of antituberculous drugs produced the isoniazid-loaded chitosan/tripolyphosphate (TPP) formulation in different chitosan/TPP ratios. The dry powder was produced with a Cyclohaler ${ }^{\circledR}$ (Teva Pharmachemie, Haarlem, The Netherlands) and in vitro evaluation showed sustained release from the formulation for up to 6 days. Release was $50 \%$ at the first 4 hours, with $80 \%$ of the total encapsulated drug released by day 6 . The effect was directly related to the chitosan/TPP ratio. Two formulations were investigated, ie, a 6:1 chitosan/TPP ratio and a 3:1 chitosan/TPP ratio, with a better long-term effect observed for the 6:1 ratio. Three types of bacteria, ie, $P$. aeruginosa, $S$. aureus, and Mycobacterium intracellulare, were included in the in vitro evaluation, and a decrease in MIC was observed for $M$. intracellulare. The efficiency of the antiproliferative effect was again associated with the chitosan/TPP ratio of $6: 1$. Different molecules were included in the construction of the dry powder formulation, with each one conferring different properties (in terms of shape and surface) to the dry powder molecule. ${ }^{100}$ The formulation contained large-sized particles, and further investigation toward creating smaller-sized dry powder, is necessary since we have positive antibacterial results in vitro. Another method of aerosol production was used for aerosolized intrapulmonary delivery of isoniazid, capreomycin, and amikacin versus subcutaneous administration of the same drugs. The Mycobacterium tuberculosis density (colony-forming units) was efficiently reduced using the aerosol and subcutaneous administration routes; however, this effect occurred one week earlier using the aerosol modality. Further evaluation of the aerosol showed positive results at lower and fewer doses, with reduction of bacteria load seen in the spleen ${ }^{101}$ (Table 3 ).

\section{Doxycycline}

Doxycycline, a tetracycline antibiotic, was administered as an aerosol using an electric nebulizer in order to evaluate its effect on mucus production in acrolein-exposed rats. Acrolein is a compound found in tobacco smoke and is known to induce chronic inflammation in the airways. Acrolein was used to induce inflammation of the airways and mucus hypersecretion in rats. Mucus hypersecretion is known to impair mucociliary clearance, so doxycycline was administered and efficiently downregulated MUC5 AC mRNA and mucus production. Doxycycline could be used in patients with severe airways inflammation, such as chronic obstructive pulmonary disease and cystic fibrosis, either as a standard anti-inflammatory treatment for mucus production or as a method for enhancing aerosol deposition. ${ }^{102}$ Doxycycline has also been found to prevent development of fibrosis in a mouse model, so there are further properties that need to be investigated $^{103}$ (Table 4).

\section{Azithromycin}

Azithromycin dry powder was evaluated in a rat model. The MMAD was measured at $3.82 \mu \mathrm{m}$ and administration was 
done with a microsprayer. Azithromycin is known to achieve high concentrations in phagocytic cells (monocytes and polymorphonuclear cells). ${ }^{104}$ Macrophages are also known to take up this dry powder when deposited in the respiratory tract as early as one hour post administration. ${ }^{105}$ The dry powder produced from raw azithromycin materials in the study by Zhang et al offers an alternative formulation for delivering this antibiotic ${ }^{67}$ (Table 4).

\section{Clindamycin}

Clindamycin was administered intratracheally either alone or in combination with dexamethasone. Animals were inoculated with Porphyromonas gingivalis. Inflammatory markers such as tumor necrosis factor- $\alpha$ (TNF- $\alpha$ ), TNF- $\alpha$ receptors (sTNFR1 and sTNFR2), interleukin $1 \beta$, and interleukin 6 , were measured at different time points. It was observed that clindamycin alone is more potent in reducing the density of the bacterial population and normalizes TNF- $\alpha$ and sTNFR1 after resolution of aspiration pneumonia ${ }^{106}$ (Table 4).

\section{Squalamine and colistin}

Squalamine, a steroid extracted from sharks, was evaluated versus colistin in a rat model. The colistin formulation was $160 \mathrm{mg}(2.8 \mu \mathrm{m}$ MMAD) and squalamine $3 \mathrm{mg}$ (3 $\mu \mathrm{m}$ MMAD), with administration for 6 days. The aerosol was administered in a sealed cage with a nose-only inlet. The rats were inoculated with $P$. aeruginosa and both treatments were found to be efficient; however, pathologic examination was in favor of the squalamine group since the diffuse and confluent bronchopneumonia lesions were markedly reduced ${ }^{107}$ (Table 3$)$.

\section{Telithromycin}

Telithromycin was administered as aerosol with a microsprayer in a rat model and the pharmacokinetics/pharmacodynamics was evaluated. The aerosol administered as $0.2 \mathrm{mg} / \mathrm{mL}$ was more efficiently distributed in alveolar macrophages and epithelial lung fluid than when administered orally. Both modalities were evaluated using the following bacteria: Haemophilus influenza, Streptococcus pneumonia, Chlamydophila pneumonia, Legionella pneumophila, Mycobacterium avium, and S. pneumonia resistant to Penicillin G, erythromycin A, and levofloxacin. It was observed that the concentration of telithromycin in the alveolar macrophages and epithelial lung fluid time curve/minimum concentration of telithromycin ratio was higher than the effective values. ${ }^{21}$ As previously stated in the amikacin section, there are specific structural properties and local transportation mechanisms which enhance the ability of a formulation to be moved more easily from the alveoli to the systemic blood circulation as inverse (Table 4).

\section{Antimicrobial aminosterol formulation}

The novel aminosterol derivative (ASD) was compared with tobramycin in a $P$. aeruginosa and $S$. aureus evaluation model. The MICs for P. aeruginosa for ASD and tobramycin were $4 \mathrm{mg} / \mathrm{L}$, and $1 \mathrm{mg} / \mathrm{L}$, respectively. The MICs for $S$. aureus for ASD and tobramycin were $1 \mathrm{mg} / \mathrm{L}$ and $0.5 \mathrm{mg} / \mathrm{L}$. The aerosol was produced using two production systems, ie, the LC Plus and eFlow, and the MMAD produced was $<5 \mu \mathrm{m}$. The effectiveness of the two aerosol formulations was further evaluated when mucin $1 \mathrm{mg} / \mathrm{mL}$ and $10 \mathrm{mg} / \mathrm{mL}$ was added. In the tobramycin group, it was observed that the MIC was increased by four-fold and 16-fold for P. aeruginosa and S. aureus, respectively. Further evaluation of this novel antimicrobial formulation is warranted in an in vivo model ${ }^{108}$ (Table 1).

\section{Production systems and evaluation models}

The two basic types of production systems are the jet nebulizer and the ultrasonic nebulizer. Jet nebulizer production is by the Bernoulli principle, and uses gas to produce an aerosol mist. The ultrasonic nebulizers use a piezoelectric crystal vibrating at a high frequency (1-3 MHz) and generate aerosol mist. The higher the frequency, the "finer" the aerosol produced. ${ }^{109}$ Aerogen's aerosol generator is portable, quiet, and has a shorter duration of aerosol production and ability to control particle size and flow rate. It efficiently aerolizes proteins and peptides, but is expensive. ${ }^{110}$ The Aeroneb hand-held inhaler has the ability to produce 3-5-fold smaller droplets when compared with the jet and ultrasonic nebulizers, and the remaining volume concentration in the residual cup is negligible, but the devices are expensive. ${ }^{111}$ Omron's technology is a piezoelectric crystal, with a negligible volume of the drug remaining in the residual cup and the ability to control particle size and flow rate, but is again an expensive device. ${ }^{112}$ TouchSpray ${ }^{\mathrm{TM}}$ technology (Odem Scientific Applications Ltd, Rehovot, Israel) also has the ability to control particle size and flow rate. It can be used to aerosolize any compound, but is expensive. ${ }^{113}$ The Soft Mist ${ }^{\circledR}$ inhaler (Boehringer Ingelheim, Ingelheim, Germany) is cheap and easy to use. The dose delivered is independent of the patient's respiratory capacity and lower doses are needed in comparison with the Handihaler device. ${ }^{114}$ Metered dose inhalers are outpatient inhalation devices, and are designed 
for single dose and multiple dose inhalation. Lung deposition varies between $12 \%-40 \%, 20 \%-25 \%$ of the cloud produced is retained within the device, lack of hand-mouth coordination is observed, and $50 \%-80 \%$ of the dose may be deposited in the oropharynx due to the high velocity of the particles produced. Patient technique is still a major factor. ${ }^{115}$ Dry powder inhalers are breath-actuated and need more rapid and larger inhalation efforts ( $>60 \mathrm{~L}$ per minute), and their efficiency depends on the nature of the powder. ${ }^{116}$

Durand et al ${ }^{59}$ investigated deposition of aerosol produced with an Atomisor NL11SN jet nebulizer connected to an $\mathrm{AOLH}^{\circledR}$ air source compressor (Diffusion Technique Française, Saint-Etienne, France). The experiment was conducted with either gentamicin solution $80 \mathrm{mg} / \mathrm{mL}$ (4 mL) or $2.5 \%$ $\mathrm{NaF}$ solution ( $4 \mathrm{~mL}$ ), with the nebulization system operating as a classic nebulizer or with addition of a $100 \mathrm{~Hz}$ acoustic frequency (producing sonic aerosol). This is the first time that intrasinus aerosol deposition has been evaluated in a human plastinated nasal cast. It was observed that the MMAD increased as the concentration of gentamicin increased, indifferent to the additional usage of $100 \mathrm{~Hz}$ acoustic flow and the local anatomic features influence the deposition. Local deposition was increased two-fold with addition of $100 \mathrm{~Hz}$ acoustic airflow, but did not overcome the local "anatomy" deposition factor. In the study by Wee et al, ${ }^{117}$ an aerosol was investigated using a method incorporating mathematical model derivation, in vitro testing, and in vivo testing.
In another study by McCormack et al, ${ }^{61}$ two different breathing modes were evaluated, ie, the tidal breathing mode and the target inhalation mode. It was observed that the target inhalation mode reduced the time of aerosol administration and increased patient adherence. The same group modified their administration apparatus to record patient adherence with aerosol administration. ${ }^{118}$ Addition of $5 \%-7 \% \mathrm{CO}_{2}$ during nebulization demonstrated an increase in tidal volume of $180 \%$ and a decrease in respiratory rate. ${ }^{119,120}$ Additional oxygen delivery through a nasal device during air-driven jet nebulization increased the fraction of inspired oxygen and decreased the droplet size produced. ${ }^{121}$

In another survey investigating the method of aerosol administration preferred by clinical physicians for tracheostomized children reported a preference for the tracheostomy aerosol mask. ${ }^{60}$ However, this was only a survey study on which device is usually preferable by pediatric pulmonologists probably due to the easy access to the airways and method of administration. Moreover, disposable versus reusable nebulizers were investigated as to whether they would have an impact on aerosol deposition. More than 20 nebulization systems were evaluated, and it was observed that there was no difference between the compressed air source and nebulizer performance; however, different interfaces produced different results. ${ }^{122}$ New nebulization systems such as the eFlow when compared with the PARI LC Star produce the aerosol in half the amount of time, but there is

Table 5 Methods and models of aerosol deposition evaluation

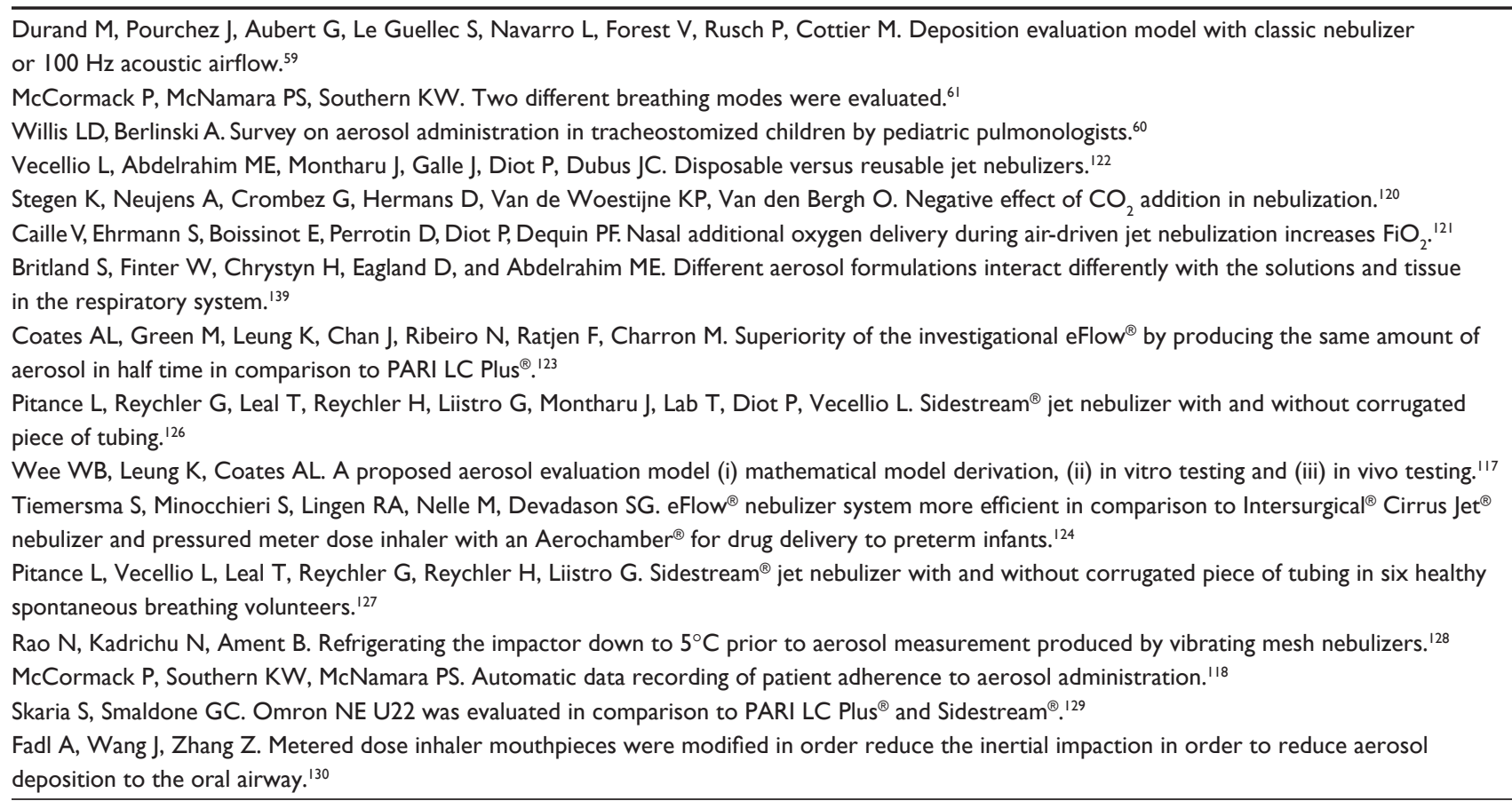


no difference in deposition rate. ${ }^{123}$ The investigational eFlow nebulizer system was observed to be more efficient than the Cirrus Jet ${ }^{\circledR}$ nebulizer (Intersurgical, Wokingham, UK) and the pressurized meter dose inhaler with an Aerochamber ${ }^{\circledR}$ (Forest Pharmaceuticals Inc, St Louis, MO, USA) for drug delivery to preterm infants. ${ }^{124}$ Further investigation of nebulization systems produced the Ink-Jet ${ }^{\circledR}$ nebulizer technology; this new apparatus was investigated with insulin solutions, and found not to interfere with the biological activity of the solution. ${ }^{125}$ This novel system of hormone administration has to be further investigated with other formulations.

Aerosol delivery (with the Sidestream ${ }^{\circledR}$ jet nebulizer, Philips Respironics, Best, The Netherlands) was observed to be efficient when it was necessary to deliver small doses rapidly; however, for high doses, nebulization was efficient when using a corrugated piece of tubing. ${ }^{126}$ This administration modality was further evaluated in six healthy spontaneous breathing volunteers. ${ }^{127}$ Regarding vibrating nebulizers, it has been proposed that refrigerating the impactor down to $5^{\circ} \mathrm{C}$ prior to aerosol measurement provides unbiased results. In addition, laser diffraction spectrometry is the optimal method for measurement of aerosol droplets produced from vibrating mesh nebulizers. ${ }^{128}$ The vibrating mesh nebulizer (Omron NE U22) was evaluated in comparison with the LC Plus and Sidestream, and it was observed that the position of the mesh device altered the run time and variability in particle distribution. ${ }^{129}$ Fadl et al ${ }^{130}$ investigated modifications in the mouthpiece of two meter dose inhalers in order to reduce inertial impact and reduce deposition of the aerosol in the oral cavity. They achieved higher particle penetration by creating a new mouthpiece based on the previous one.

\section{Conclusion}

Local antibiotic administration has shown favorable results in the treatment of respiratory diseases. The droplets produced with the current systems vary in the range of $1.2-4.5 \mu \mathrm{m}$, and we would like to have aerosols of $1-2 \mu$ m upon production since until their final deposition they will expand at least by $25 \%$. The particle size of $1-2 \mu \mathrm{m}$ deposits in the 17-23 airway generations which are the respiratory airways. ${ }^{131,132}$ The method of aerosol production and delivery may vary between patients due to the underlying respiratory disease or respiratory capability (eg, chronic obstructive pulmonary disease, cystic fibrosis, and intubation). ${ }^{3,77,133-136}$ The drug formulation is also an important factor in deposition and local absorption, and further investigation is needed probably in a disease by disease case. ${ }^{137-140}$ However, the appropriate timing of aerosol antibiotic administration has not been properly evaluated in all respiratory diseases. Apart from the obvious issue of pharmacokinetics, the timing of administration as prophylactic treatment has to be further evaluated in comparison with intravenous administration in head-to-head trials. ${ }^{141}$ In any case, we are interested in creating a local antibiotic concentration gradient that will not induce antibiotic resistance. ${ }^{133,142}$ Administration of aerosol antibiotic or antiviral therapy in acute infection was previously administered without toxicity. ${ }^{143}$ Future direction towards an efficient aerosol antibiotic treatment comes from a group of patients in need of daily treatment. Studies in children and young adults with cystic fibrosis indicate that the next generation of aerosol antibiotic treatments should be delivered in less time and less dose frequency during the day. ${ }^{144}$ Moreover, a patient-friendly device that increases adherence and possibly enables monitoring of treatment should be investigated further. ${ }^{118}$ These parameters have been partially achieved with carriers (eg, liposomes, PEG, chitosan $)^{53,58,63,69,71,72}$ encapsulating the antibiotic drug and with new aerosol production systems (eg, eFlow) ${ }^{124}$ and mouthpiece modifications. ${ }^{126}$ Three directions of investigation should summarized to (i) production system, (ii) efficient interface of production to deposition, and (iii) efficient local concentration $\left(\mathrm{MIC}_{\max }\right.$ ) (Table 5).

\section{Disclosure}

The authors report no conflicts of interest in this work.

\section{References}

1. Zhang L, Huang Y, Zhou Y, Buckley T, Wang HH. Antibiotic administration routes significantly influence the levels of antibiotic resistance in gut microbiota. Antimicrob Agents Chemother. 2013;57(8):3659-3666.

2. Young SW, Zhang M, Freeman JT, Mutu-Grigg J, Pavlou P, Moore GA. The Mark Coventry Award: higher tissue concentrations of vancomycin with low-dose intraosseous regional versus systemic prophylaxis in TKA: a randomized trial. Clin Orthop Relat Res. May 11, 2013. [Epub ahead of print.]

3. Smaldone GC. Advances in aerosols: adult respiratory disease. J Aerosol Med. 2006;19(1):36-46.

4. Houtmeyers E, Gosselink R, Gayan-Ramirez G, Decramer M. Regulation of mucociliary clearance in health and disease. Eur Respir J. 1999;13(5):1177-1188.

5. Clay MM, Pavia D, Newman SP, Clarke SW. Factors influencing the size distribution of aerosols from jet nebulisers. Thorax. 1983;38(10): 755-759.

6. Smith EC, Denyer J, Kendrick AH. Comparison of twenty three nebulizer/compressor combinations for domiciliary use. Eur Respir J. 1995;8(7):1214-1221.

7. Douglas JG, Leslie MJ, Crompton GK, Grant IW. Is the flow rate used to drive a jet nebuliser clinically important? $\mathrm{Br}$ Med J (Clin Res Ed). 1985;290(6461):29.

8. Newman SP, Pellow PG, Clay MM, Clarke SW. Evaluation of jet nebulisers for use with gentamicin solution. Thorax. 1985;40(9): 671-676.

9. Byron PR, editor. Aerosol formulation, generation and delivery using non-metered systems. In: Respiratory Drug Delivery. Boca Raton, FL: CRC Press; 1990. 
10. Kendrick AH, Smith EC, Denyer J. Nebulizers - fill volume, residual volume and matching of nebulizer to compressor. Respir Med. 1995;89(3):157-159.

11. Zarogoulidis P, Kioumis I, Ritzoulis C, et al. New insights in the production of aerosol antibiotics. Evaluation of the optimal aerosol production system for ampicillin-sulbactam, meropenem, ceftazidime, cefepime and piperacillin-tazobactam. Int J Pharm. July 23, 2013. [Epub ahead of print.]

12. Kendrick AH, Smith EC, Wilson RS. Selecting and using nebuliser equipment. Thorax. 1997;52 Suppl 2:S92-S101.

13. Kwok PC, Trietsch SJ, Kumon M, Chan HK. Electrostatic charge characteristics of jet nebulized aerosols. J Aerosol Med Pulm Drug Deliv. 2010;23(3):149-159.

14. Davis SS, Bubb MD. Physico-chemical studies on aerosol solutions for drug delivery. 3 The effect of relative humidity on the particle size of inhalation aerosols. Int J Pharm. 1978;6(1):303-314.

15. Davis SS, Warburton B. Physico-chemical studies on aerosol solutions for drug delivery. I. Water-propylene glycol studies. Int J Pharm. 1978;(1):71-83.

16. Newman SP, Pellow PGD, Clarke SW. Drop sizes from medical atomisers (nebulisers) for drug solutions of different viscosities and surface tensions. Atom Spray Technol. 1987;(3):1-11.

17. Labiris NR, Dolovich MB. Pulmonary drug delivery. Part I: physiological factors affecting therapeutic effectiveness of aerosolized medications. Br J Clin Pharmacol. 2003;56(6):588-599.

18. Nunn JF. Nunn's Applied Respiratory Physiology. 4th ed. Oxford, UK Butterworth-Heineman; 1993.

19. Zarogoulidis P, Papanas N, Kouliatsis G, Spyratos D, Zarogoulidis K, Maltezos E. Inhaled insulin: too soon to be forgotten? J Aerosol Med Pulm Drug Deliv. 2011;24(5):213-223.

20. Suresh Babu K, Kastelik J, Morjaria JB. Role of long term antibiotics in chronic respiratory diseases. Respir Med. 2013;107(6):800-815.

21. Togami K, Chono S, Morimoto K. Aerosol-based efficient delivery of clarithromycin, a macrolide antimicrobial agent, to lung epithelial lining fluid and alveolar macrophages for treatment of respiratory infections. J Aerosol Med Pulm Drug Deliv. 2012;25(2):110-115.

22. Otterson GA, Villalona-Calero MA, Hicks W, et al. Phase I/II study of inhaled doxorubicin combined with platinum-based therapy for advanced non-small cell lung cancer. Clin Cancer Res. 2010;16(8): 2466-2473.

23. Zarogoulidis P, Eleftheriadou E, Sapardanis I, et al. Feasibility and effectiveness of inhaled carboplatin in NSCLC patients. Invest New Drugs. 2012;30(4):1628-1640.

24. Zarogoulidis P, Chatzaki E, Porpodis K, et al. Inhaled chemotherapy in lung cancer: future concept of nanomedicine. Int J Nanomedicine. 2012;7:1551-1572.

25. Darwiche K, Zarogoulidis P, Karamanos NK, et al. Efficacy versus safety concerns for aerosol chemotherapy in non-small-cell lung cancer: a future dilemma for micro-oncology. Future Oncol. 2013;9(4) 505-525.

26. Geller DE, Pitlick WH, Nardella PA, Tracewell WG, Ramsey BW. Pharmacokinetics and bioavailability of aerosolized tobramycin in cystic fibrosis. Chest. 2002;122(1):219-226.

27. Ramsey BW, Pepe MS, Quan JM, et al. Intermittent administration of inhaled tobramycin in patients with cystic fibrosis. Cystic Fibrosis Inhaled Tobramycin Study Group. N Engl J Med. 1999;340(1): 23-30.

28. Moss RB. Long-term benefits of inhaled tobramycin in adolescent patients with cystic fibrosis. Chest. 2002;121(1):55-63.

29. Moss RB. Administration of aerosolized antibiotics in cystic fibrosis patients. Chest. 2001;120(Suppl 3):107S-113S.

30. Murphy TD, Anbar RD, Lester LA, et al. Treatment with tobramycin solution for inhalation reduces hospitalizations in young CF subjects with mild lung disease. Pediatr Pulmonol. 2004;38(4):314-320.

31. Geller DE, Madge S. Technological and behavioral strategies to reduce treatment burden and improve adherence to inhaled antibiotics in cystic fibrosis. Respir Med. 2011;105 Suppl 2:S24-S31.
32. Chuchalin A, Csiszer E, Gyurkovics K, et al. A formulation of aerosolized tobramycin (Bramitob) in the treatment of patients with cystic fibrosis and Pseudomonas aeruginosa infection: a double-blind, placebocontrolled, multicenter study. Paediatr Drugs. 2007;9 Suppl 1:21-31.

33. Flume PA, O'Sullivan BP, Robinson KA, et al. Cystic fibrosis pulmonary guidelines: chronic medications for maintenance of lung health. Am J Respir Crit Care Med. 2007;176(10):957-969.

34. Gibson RL, Retsch-Bogart GZ, Oermann C, et al. Microbiology, safety, and pharmacokinetics of aztreonam lysinate for inhalation in patients with cystic fibrosis. Pediatr Pulmonol. 2006;41(7):656-665.

35. Retsch-Bogart GZ, Burns JL, Otto KL, et al. A phase 2 study of aztreonam lysine for inhalation to treat patients with cystic fibrosis and Pseudomonas aeruginosa infection. Pediatr Pulmonol. 2008;43(1):47-58.

36. Retsch-Bogart GZ, Quittner AL, Gibson RL, et al. Efficacy and safety of inhaled aztreonam lysine for airway pseudomonas in cystic fibrosis. Chest. 2009;135(5):1223-1232.

37. McCoy KS, Quittner AL, Oermann CM, Gibson RL, Retsch-Bogart GZ, Montgomery AB. Inhaled aztreonam lysine for chronic airway Pseudomonas aeruginosa in cystic fibrosis. Am J Respir Crit Care Med. 2008;178(9):921-928.

38. Oermann CM, Retsch-Bogart GZ, Quittner AL, et al. An 18-month study of the safety and efficacy of repeated courses of inhaled aztreonam lysine in cystic fibrosis. Pediatr Pulmonol. 2010;45(11): $1121-1134$.

39. Oermann CM, McCoy KS, Retsch-Bogart GZ, Gibson RL, McKevitt M, Montgomery AB. Pseudomonas aeruginosa antibiotic susceptibility during long-term use of aztreonam for inhalation solution (AZLI). J Antimicrob Chemother. 2011;66(10):2398-2404.

40. Wainwright CE, Quittner AL, Geller DE, et al. Aztreonam for inhalation solution (AZLI) in patients with cystic fibrosis, mild lung impairment, and P. aeruginosa. J Cyst Fibros. 2011;10(4):234-242.

41. Hansen CR, Pressler T, Hoiby N. Early aggressive eradication therapy for intermittent Pseudomonas aeruginosa airway colonization in cystic fibrosis patients: 15 years experience. J Cyst Fibros. 2008;7(6): $523-530$.

42. Jensen T, Pedersen SS, Garne S, Heilmann C, Hoiby N, Koch C. Colistin inhalation therapy in cystic fibrosis patients with chronic Pseudomonas aeruginosa lung infection. J Antimicrob Chemother. 1987;19(6): $831-838$.

43. Hodson ME, Gallagher CG, Govan JR. A randomised clinical trial of nebulised tobramycin or colistin in cystic fibrosis. Eur Respir $J$. 2002;20(3):658-664.

44. Heijerman H, Westerman E, Conway S, Touw D, Doring G. Inhaled medication and inhalation devices for lung disease in patients with cystic fibrosis: a European consensus. J Cyst Fibros. 2009;8(5):295-315.

45. Beringer $P$. The clinical use of colistin in patients with cystic fibrosis. Curr Opin Pulm Med. 2001;7(6):434-440.

46. McCoy KS. Compounded colistimethate as possible cause of fatal acute respiratory distress syndrome. $N$ Engl J Med. 2007;357(22): 2310-2311.

47. European Medicines' Agency. Colobreathe. Available from: http:// www.ema.europa.eu/ema/index.jsp?curl=pages/medicines/human/ medicines/001225/smops/Positive/human_smop_000270.jsp\&mid= WC0b01ac058001d127\&jsenabled=true. Accessed August 23, 2013.

48. Geller DE, Weers J, Heuerding S. Development of an inhaled drypowder formulation of tobramycin using PulmoSphere technology. J Aerosol Med Pulm Drug Deliv. 2011;24(4):175-182.

49. Geller DE, Konstan MW, Smith J, Noonberg SB, Conrad C. Novel tobramycin inhalation powder in cystic fibrosis subjects: pharmacokinetics and safety. Pediatr Pulmonol. 2007;42(4): 307-313.

50. Konstan MW, Flume PA, Kappler M, et al. Safety, efficacy and convenience of tobramycin inhalation powder in cystic fibrosis patients: the EAGER trial. J Cyst Fibros. 2011;10(1):54-61.

51. PARI Pharma GmbH. eFlow ${ }^{\circledR}$ Technology Advanced Aerosol Delivery Platform. Starnberg, Germany: PARI Pharma GmbH; 2011. Available from: http://www.paripharma.com. Accessed August 25, 2013. 
52. Insmed Incorporated. Arikace ${ }^{\circledR}$ (Inhaled liposomal amikacin). Monmouth Junction, NJ: Insmed Incorporated; 2011. Available from: http:// www.insmed.com/arikace.php\#p1. Accessed August 25, 2013.

53. Meers $\mathrm{P}$, Neville M, Malinin V, et al. Biofilm penetration, triggered release and in vivo activity of inhaled liposomal amikacin in chronic Pseudomonas aeruginosa lung infections. J Antimicrob Chemother. 2008;61(4):859-868.

54. King P, Lomovskaya O, Griffith DC, Burns JL, Dudley MN. In vitro pharmacodynamics of levofloxacin and other aerosolized antibiotics under multiple conditions relevant to chronic pulmonary infection in cystic fibrosis. Antimicrob Agents Chemother. 2010;54(1): $143-148$.

55. King P, Citron DM, Griffith DC, Lomovskaya O, Dudley MN. Effect of oxygen limitation on the in vitro activity of levofloxacin and other antibiotics administered by the aerosol route against Pseudomonas aeruginosa from cystic fibrosis patients. Diagn Microbiol Infect Dis. 2010;66(2):181-186.

56. Trapnell BC, McColley SA, Kissner DG, et al. Fosfomycin/tobramycin for inhalation in patients with cystic fibrosis with pseudomonas airway infection. Am J Respir Crit Care Med. 2012;185(2):171-178.

57. Son YJ, McConville JT. A new respirable form of rifampicin. Eur J Pharm Biopharm. 2011;78(3):366-376.

58. Ong HX, Traini D, Cipolla D, et al. Liposomal nanoparticles control the uptake of ciprofloxacin across respiratory epithelia. Pharm Res. 2012;29(12):3335-3346.

59. Durand M, Pourchez J, Aubert G, et al. Impact of acoustic airflow nebulization on intrasinus drug deposition of a human plastinated nasal cast: new insights into the mechanisms involved. Int $J$ Pharm. 2011;421(1):63-71.

60. Willis LD, Berlinski A. Survey of aerosol delivery techniques to spontaneously breathing tracheostomized children. Respir Care. 2012;57(8):1234-1241.

61. McCormack P, McNamara PS, Southern KW. A randomised controlled trial of breathing modes for adaptive aerosol delivery in children with cystic fibrosis. J Cyst Fibros. 2011;10(5):343-349.

62. Parkins MD, Elborn JS. Tobramycin inhalation powder: a novel drug delivery system for treating chronic Pseudomonas aeruginosa infection in cystic fibrosis. Expert Rev Respir Med. 2011;5(5):609-622.

63. Pourshahab PS, Gilani K, Moazeni E, Eslahi H, Fazeli MR, Jamalifar H. Preparation and characterization of spray dried inhalable powders containing chitosan nanoparticles for pulmonary delivery of isoniazid. J Microencapsul. 2011;28(7):605-613.

64. Chan JG, Chan HK, Prestidge CA, Denman JA, Young PM, Traini D. A novel dry powder inhalable formulation incorporating three first-line anti-tubercular antibiotics. Eur J Pharm Biopharm. September 13, 2012. [Epub ahead of print.]

65. Chuealee R, Wiedmann TS, Srichana T. Physicochemical properties and antifungal activity of amphotericin B incorporated in cholesteryl carbonate esters. J Pharm Sci. 2011;100(5):1727-1735.

66. Nasr M, Nawaz S, Elhissi A. Amphotericin B lipid nanoemulsion aerosols for targeting peripheral respiratory airways via nebulization. Int J Pharm. 2012;436(1-2):611-616.

67. Zhang Y, Wang X, Lin X, Liu X, Tian B, Tang X. High azithromycin loading powders for inhalation and their in vivo evaluation in rats. Int J Pharm. 2010;395(1-2):205-214.

68. Parkins MD, Elborn JS. Aztreonam lysine: a novel inhalational antibiotic for cystic fibrosis. Expert Rev Respir Med. 2010;4(4): 435-444.

69. Gilani K, Moazeni E, Ramezanli T, Amini M, Fazeli MR, Jamalifar H. Development of respirable nanomicelle carriers for delivery of amphotericin B by jet nebulization. J Pharm Sci. 2011;100(1):252-259.

70. Son YJ, McConville JT. Preparation of sustained release rifampicin microparticles for inhalation. J Pharm Pharmacol. 2012;64(9): 1291-1302.

71. Abdulla JM, Tan YT, Darwis Y. Rehydrated lyophilized rifampicinloaded mPEG-DSPE formulations for nebulization. AAPS PharmSciTech. 2010;11(2):663-671.
72. Alexander BD, Winkler TP, Shi S, Dodds Ashley ES, Hickey AJ. In vitro characterization of nebulizer delivery of liposomal amphotericin B aerosols. Pharm Dev Technol. 2011;16(6):577-582.

73. Stelmach I, Korzeniewska A, Stelmach W. Long-term benefits of inhaled tobramycin in children with cystic fibrosis: first clinical observations from Poland. Respiration. 2008;75(2):178-181.

74. Briesacher BA, Quittner AL, Saiman L, Sacco P, Fouayzi H, Quittell LM. Adherence with tobramycin inhaled solution and health care utilization. BMC Pulm Med. 2011;11:5.

75. Konstan MW, Geller DE, Minic P, Brockhaus F, Zhang J, Angyalosi G. Tobramycin inhalation powder for P. aeruginosa infection in cystic fibrosis: the EVOLVE trial. Pediatr Pulmonol. October 20, 2010. [Epub ahead of print.]

76. Bhavsar T, Liu M, Liu X, Cantor J. Aerosolized recombinant human lysozyme enhances the bactericidal effect of tobramycin in a hamster model of Pseudomonas aeruginosa-induced pneumonia. Exp Lung Res. 2011;37(9):536-541.

77. Ghannam DE, Rodriguez GH, Raad II, Safdar A. Inhaled aminoglycosides in cancer patients with ventilator-associated Gram-negative bacterial pneumonia: safety and feasibility in the era of escalating drug resistance. Eur J Clin Microbiol Infect Dis. 2009;28(3):253-259.

78. Aquino RP, Prota L, Auriemma G, et al. Dry powder inhalers of gentamicin and leucine: formulation parameters, aerosol performance and in vitro toxicity on CuFi1 cells. Int J Pharm. 2012;426(1-2):100-107.

79. Leong KW, Ong S, Chee HL, Lee W, Kwa AL. Hypersensitivity pneumonitis due to high-dose colistin aerosol therapy. Int J Infect Dis. 2010;14(11):e1018-e1019.

80. Wood GC. Aerosolized antibiotics for treating hospital-acquired and ventilator-associated pneumonia. Expert Rev Anti Infect Ther. 2011;9(11):993-1000.

81. Lu Q, Luo R, Bodin L, et al. Efficacy of high-dose nebulized colistin in ventilator-associated pneumonia caused by multidrug-resistant Pseudomonas aeruginosa and Acinetobacter baumannii. Anesthesiology. 2012;117(6):1335-1347.

82. Safdar A. Aerosolized amikacin in patients with difficult-to-treat pulmonary nontuberculous mycobacteriosis. Eur J Clin Microbiol Infect Dis. 2012;31(8):1883-1887.

83. Tsivkovskii R, Sabet M, Tarazi Z, Griffith DC, Lomovskaya O, Dudley MN. Levofloxacin reduces inflammatory cytokine levels in human bronchial epithelia cells: implications for aerosol MP-376 (levofloxacin solution for inhalation) treatment of chronic pulmonary infections. FEMS Immunol Med Microbiol. 2011;61(2):141-146.

84. Zarogoulidis P, Papanas N, Kioumis I, Chatzaki E, Maltezos E, Zarogoulidis K. Macrolides: from in vitro anti-inflammatory and immunomodulatory properties to clinical practice in respiratory diseases. Eur J Clin Pharmacol. 2012;68(5):479-503.

85. Peterson JW, Moen ST, Healy D, et al. Protection afforded by fluoroquinolones in animal models of respiratory infections with Bacillus anthracis, Yersinia pestis, and Francisella tularensis. Open Microbiol J. 2010;4:34-46.

86. Baldwin DR, Honeybourne D, Wise R. Pulmonary disposition of antimicrobial agents: methodological considerations. Antimicrob Agents Chemother. 1992;36(6):1171-1175.

87. Wang F, Daugherty B, Keise LL, et al. Heterogeneity of claudin expression by alveolar epithelial cells. Am J Respir Cell Mol Biol. 2003;29(1):62-70.

88. Campbell L, Abulrob AN, Kandalaft LE, et al. Constitutive expression of P-glycoprotein in normal lung alveolar epithelium and functionality in primary alveolar epithelial cultures. J Pharmacol Exp Ther. 2003;304(1):441-452.

89. Fojo AT, Ueda K, Slamon DJ, Poplack DG, Gottesman MM, Pastan I. Expression of a multidrug-resistance gene in human tumors and tissues. Proc Natl Acad Sci U SA. 1987;84(1):265-269.

90. Zaman GJ, Versantvoort CH, Smit JJ, et al. Analysis of the expression of MRP, the gene for a new putative transmembrane drug transporter, in human multidrug resistant lung cancer cell lines. Cancer Res. 1993;53(8):1747-1750. 
91. Togami K, Chono S, Morimoto K. Distribution characteristics of clarithromycin and azithromycin, macrolide antimicrobial agents used for treatment of respiratory infections, in lung epithelial lining fluid and alveolar macrophages. Biopharm Drug Dispos. 2011;32(7): 389-397.

92. Geist LJ, Powers LS, Monick MM, Hunninghake GW. Asbestos stimulation triggers differential cytokine release from human monocytes and alveolar macrophages. Exp Lung Res. 2000;26(1):41-56.

93. Mao JT, Roth MD, Serio KJ, et al. Celecoxib modulates the capacity for prostaglandin E2 and interleukin-10 production in alveolar macrophages from active smokers. Clin Cancer Res. 2003;9(16 Pt 1): 5835-5841

94. Ogle CK, Ogle JD, Johnson C, Keynton L, Alexander JW. The production of C3, PGE2 and TxB2 by splenic, alveolar, and peritoneal guinea pig macrophages. Prostaglandins. 1988;36(3):279-289.

95. Rennard SI, Hunninghake GW, Bitterman PB, Crystal RG. Production of fibronectin by the human alveolar macrophage: mechanism for the recruitment of fibroblasts to sites of tissue injury in interstitial lung diseases. Proc Natl Acad Sci U S A. 1981;78(11):7147-7151.

96. Weissbach S, Neuendank A, Pettersson M, Schaberg T, Pison U. Surfactant protein A modulates release of reactive oxygen species from alveolar macrophages. Am J Physiol. 1994;267(6 Pt 1): L660-L666.

97. Allen TM. Liposomal drug formulations. Rationale for development and what we can expect for the future. Drugs. 1998;56(5):747-756.

98. Klonne DR, Dodd DE, Losco PE, Troup CM, Tyler TR. Two-week aerosol inhalation study on polyethylene glycol (PEG) 3350 in F-344 rats. Drug Chem Toxicol. 1989;12(1):39-48.

99. Zhou L, Li Z, Liu Z, Ren J, Qu X. Luminescent carbon dot-gated nanovehicles for ph-triggered intracellular controlled release and imaging. Langmuir. 2013;29(21):6396-6403.

100. Zarogoulidis P, Hohenforst-Schmidt W, Darwiche K, et al. 2-diethylaminoethyl-dextran methyl methacrylate copolymer nonviral vector: still a long way toward the safety of aerosol gene therapy. Gene Ther. May 30, 2013. [Epub ahead of print.]

101. Gonzalez-Juarrero M, Woolhiser LK, Brooks E, DeGroote MA, Lenaerts AJ. Mouse model for efficacy testing of antituberculosis agents via intrapulmonary delivery. Antimicrob Agents Chemother. 2012;56(7):3957-3959.

102. Ren S, Guo LL, Yang J, et al. Doxycycline attenuates acrolein-induced mucin production, in part by inhibiting MMP-9. Eur J Pharmacol. 2011;650(1):418-423.

103. Ward JE, Ren R, Toraldo G, et al. Doxycycline reduces fibril formation in a transgenic mouse model of AL amyloidosis. Blood. 2011;118(25) 6610-6617.

104. Hall IH, Schwab UE, Ward ES, Butts JD, Wolford ET, Ives TJ. Disposition and intracellular activity of azithromycin in human THP-1 acute monocytes. Int J Antimicrob Agents. 2002;20(5):348-360.

105. Bosquillon C, Preat V, Vanbever R. Pulmonary delivery of growth hormone using dry powders and visualization of its local fate in rats. J Control Release. 2004;96(2):233-244.

106. Nemec A, Pavlica Z, Nemec-Svete A, Erzen D, Milutinovic A, Petelin M. Aerosolized clindamycin is superior to aerosolized dexamethasone or clindamycin-dexamethasone combination in the treatment of severe Porphyromonas gingivalis aspiration pneumonia in an experimental murine model. Exp Lung Res. 2012;38(1):9-18.

107. Hraiech S, Bregeon F, Brunel JM, et al. Antibacterial efficacy of inhaled squalamine in a rat model of chronic Pseudomonas aeruginosa pneumonia. J Antimicrob Chemother. 2012;67(10):2452-2458.

108. Alhanout K, Brunel JM, Dubus JC, Rolain JM, Andrieu V. Suitability of a new antimicrobial aminosterol formulation for aerosol delivery in cystic fibrosis. J Antimicrob Chemother. 2011;66(12): 2797-2800.

109. Labiris NR, Dolovich MB. Pulmonary drug delivery. Part II: the role of inhalant delivery devices and drug formulations in therapeutic effectiveness of aerosolized medications. Br J Clin Pharmacol. 2003;56(6): 600-612.
110. Hess DR. Nebulizers: principles and performance. Respir Care. 2000;45(6):609-622.

111. Ari A, Areabi H, Fink JB. Evaluation of aerosol generator devices at 3 locations in humidified and non-humidified circuits during adult mechanical ventilation. Respir Care. 2010;55(7):837-844.

112. Dhand R. Nebulizers that use a vibrating mesh or plate with multiple apertures to generate aerosol. Respir Care. 2002;47(12): 1406-1416.

113. Abu-Rabie P, Denniff P, Spooner N, Brynjolffssen J, Galluzzo P, Sanders G. Method of applying internal standard to dried matrix spot samples for use in quantitative bioanalysis. Anal Chem. 2011;83(22): 8779-8786.

114. Zierenberg B. Optimizing the in vitro performance of Respimat. J Aerosol Med. 1999;12 Suppl 1:S19-S24.

115. Dolovich M. New propellant-free technologies under investigation. J Aerosol Med. 1999;12 Suppl 1:S9-S17.

116. Newman SP, Weisz AW, Talaee N, Clarke SW. Improvement of drug delivery with a breath actuated pressurised aerosol for patients with poor inhaler technique. Thorax. 1991;46(10):712-716.

117. Wee WB, Leung K, Coates AL. Modeling breath-enhanced jet nebulizers to estimate pulmonary drug deposition. J Aerosol Med Pulm Drug Deliv. March 29, 2013. [Epub ahead of print.]

118. McCormack P, Southern KW, McNamara PS. New nebulizer technology to monitor adherence and nebulizer performance in cystic fibrosis J Aerosol Med Pulm Drug Deliv. 2012;25(6):307-309.

119. Davis JN, Stagg D. Interrelationships of the volume and time components of individual breaths in resting man. J Physiol. 1975;245(2): 481-498.

120. Stegen K, Neujens A, Crombez G, Hermans D, Van de Woestijne KP, Van den Bergh O. Negative affect, respiratory reactivity, and somatic complaints in a $\mathrm{CO} 2$ enriched air inhalation paradigm. Biol Psychol. 1998;49(1-2):109-122.

121. Caille V, Ehrmann S, Boissinot E, Perrotin D, Diot P, Dequin PF. Influence of jet nebulization and oxygen delivery on the fraction of inspired oxygen: an experimental model. J Aerosol Med Pulm Drug Deliv. 2009;22(3):255-261.

122. Vecellio L, Abdelrahim ME, Montharu J, Galle J, Diot P, Dubus JC. Disposable versus reusable jet nebulizers for cystic fibrosis treatment with tobramycin. J Cyst Fibros. 2011;10(2):86-92.

123. Coates AL, Green M, Leung K, et al. A comparison of amount and speed of deposition between the PARI LC STAR(R) jet nebulizer and an investigational eFlow(R) nebulizer. J Aerosol Med Pulm Drug Deliv. 2011;24(3):157-163.

124. Tiemersma S, Minocchieri S, Lingen RA, Nelle M, Devadason SG Vibrating membrane devices deliver aerosols more efficient than standard devices: a study in a neonatal upper airway model. J Aerosol Med Pulm Drug Deliv. October 28, 2012. [Epub ahead of print.]

125. Nemoto M, Hiki Y, Shimada K, et al. Novel hormonal delivery method using the ink-jet technology: application to pulmonary insulin therapies. Diabetes Technol Ther. 2011;13(5):509-517.

126. Pitance L, Reychler G, Leal T, et al. Aerosol delivery to the lung is more efficient using an extension with a standard jet nebulizer than an open-vent jet nebulizer. J Aerosol Med Pulm Drug Deliv. 2013;26(4): 208-214.

127. Pitance L, Vecellio L, Leal T, Reychler G, Reychler H, Liistro G. Delivery efficacy of a vibrating mesh nebulizer and a jet nebulizer under different configurations. J Aerosol Med Pulm Drug Deliv. 2010;23(6):389-396.

128. Rao N, Kadrichu N, Ament B. Application of a droplet evaporation model to aerodynamic size measurement of drug aerosols generated by a vibrating mesh nebulizer. J Aerosol Med Pulm Drug Deliv. 2010;23(5):295-302.

129. Skaria S, Smaldone GC. Omron NE U22: comparison between vibrating mesh and jet nebulizer. J Aerosol Med Pulm Drug Deliv. 2010;23(3):173-180.

130. Fadl A, Wang J, Zhang Z. Metered-dose inhaler efficiency enhancement: a case study and novel design. Inhal Toxicol. 2010;22(7):601-609. 
131. Standaert TA, Vandevanter D, Ramsey BW, et al. The choice of compressor effects the aerosol parameters and the delivery of tobramycin from a single model nebulizer. JAerosol Med. 2000;13(2): 147-153.

132. Hurley PK, Smye SW, Cunliffe H. Assessment of antibiotic aerosol generation using commercial jet nebulizers. JAerosol Med. 1994;7(3): 217-228.

133. Rottier BL, de Boer AH, Duiverman EJ. Inhaled medication and inhalation devices for lung disease in patients with cystic fibrosis: three areas for future research. Which areas to target? Which particle size to deliver? Which device to use? J Cyst Fibros. 2010;9(4): 296-297.

134. Rubin BK. Aerosolized antibiotics for non-cystic fibrosis bronchiectasis. J Aerosol Med Pulm Drug Deliv. 2008;21(1):71-76.

135. Dhand R. Aerosol delivery during mechanical ventilation: from basic techniques to new devices. J Aerosol Med Pulm Drug Deliv. 2008;21(1):45-60.

136. el Din MA, Palmer LB, el Tayeb MN, Khalil I, Gabr MS. Nebulizer therapy with antibiotics in chronic suppurative lung disease. J Aerosol Med. 1994;7(4):345-350.

137. Lange CF, Finlay WH. Liquid atomizing: nebulizing and other methods of producing aerosols. J Aerosol Med. 2006;19(1):28-35.
138. Hasan MA, Lange CF. Estimating in vivo airway surface liquid concentration in trials of inhaled antibiotics. J Aerosol Med. 2007;20(3): 282-293.

139. Britland S, Finter W, Chrystyn H, Eagland D, Abdelrahim ME. Droplet aerodynamics, cellular uptake, and efficacy of a nebulizable corticosteroid nanosuspension are superior to a micronized dosage form. Biotechnol Prog. 2012;28(5):1152-1159.

140. Diot P, Dequin PF, Rivoire B, et al. Aerosols and anti-infectious agents. J Aerosol Med. 2001;14(1):55-64.

141. Lo D, VanDevanter DR, Flume P, Smyth A. Aerosolized antibiotic therapy for chronic cystic fibrosis airway infections: continuous or intermittent? Respir Med. 2011;105 Suppl 2:S9-S17.

142. Todisco T, Eslami A, Baglioni S, et al. Basis for nebulized antibiotics: droplet characterization and in vitro antimicrobial activity versus Staphylococcus aureus, Escherichia coli, and Pseudomonas aeruginosa. J Aerosol Med. 2000;13(1):11-16.

143. Takanami C, Goto Y. Physical properties of antibiotic aerosols produced by jet and ultrasonic nebulizers. J Aerosol Med. 1990;3(1): 45-52.

144. Ruddy J, Emerson J, Moss R, et al. Sputum tobramycin concentrations in cystic fibrosis patients with repeated administration of inhaled tobramycin. J Aerosol Med Pulm Drug Deliv. 2013;26(2):69-75.
Drug Design, Development and Therapy

\section{Publish your work in this journal}

Drug Design, Development and Therapy is an international, peerreviewed open-access journal that spans the spectrum of drug design and development through to clinical applications. Clinical outcomes, patient safety, and programs for the development and effective, safe, and sustained use of medicines are a feature of the journal, which

\section{Dovepress}

has also been accepted for indexing on PubMed Central. The manuscript management system is completely online and includes a very quick and fair peer-review system, which is all easy to use. Visit http://www.dovepress.com/testimonials.php to read real quotes from published authors.

Submit your manuscript here: http://www.dovepress.com/drug-design-development-and-therapy-journal 